NBER WORKING PAPER SERIES

\title{
PHYSICIAN CHARACTERISTICS AND PATIENT SURVIVAL: EVIDENCE FROM PHYSICIAN AVAILABILITY
}

\author{
Joseph J. Doyle Jr. \\ Working Paper 27458 \\ http://www.nber.org/papers/w27458 \\ NATIONAL BUREAU OF ECONOMIC RESEARCH \\ 1050 Massachusetts Avenue \\ Cambridge, MA 02138 \\ July 2020
}

I thank Charlie Brown, Michele Belot, Janet Currie, Gordon Dahl, Francesco Decarolis, David Dranove, Andrea Ichino, Chris Knittel, Steven Levitt, Bentley MacLeod, Doug Miller, Kevin Murphy, Mel Stephens, Tavneet Suri, and seminar participants at the Bocconi University, Cornell University, European University Institute, University of Bologna, Ca'Forsci University, Einaudi Institute for Economics and Finance, Georgetown University, Paris School of Economics, Prague University of Economics, University of Bergen, University of Copenhagen, University of California at San Diego, University of Chicago, University of Michigan, University of Verona, University of Virginia, University of Zurich, for helpful suggestions. I thank Mauricio Caceres and Kyle Barron for excellent research assistance. I gratefully acknowledge support from the National Institutes of Health R01 AG041974. The views expressed herein are those of the author and do not necessarily reflect the views of the National Bureau of Economic Research.

NBER working papers are circulated for discussion and comment purposes. They have not been peer-reviewed or been subject to the review by the NBER Board of Directors that accompanies official NBER publications.

(C) 2020 by Joseph J. Doyle Jr.. All rights reserved. Short sections of text, not to exceed two paragraphs, may be quoted without explicit permission provided that full credit, including () notice, is given to the source. 
Physician Characteristics and Patient Survival: Evidence from Physician Availability

Joseph J. Doyle Jr.

NBER Working Paper No. 27458

July 2020

JEL No. I10

\begin{abstract}
$\underline{\text { ABSTRACT }}$
Measuring physician quality is fundamental to understanding healthcare productivity, yet patient sorting can confound attempts to estimate the types of physicians that improve survival. This paper aims to overcome selection bias by exploiting plausibly exogenous variation in the mix of physicians available to treat patients when they are admitted to the hospital via the emergency department. One innovation is the construction of proxy measures for the types of physicians available using $100 \%$ Medicare claims data. Physician characteristics considered include specialty training, medical school quality rankings, sex, years of experience, and patient volume. The main finding is that when heart failure patients enter the hospital when more cardiologists are available, they are more likely to be treated directly by a cardiologist, have more invasive procedures, and survive over the following year.
\end{abstract}

Joseph J. Doyle Jr.

MIT Sloan School of Management

100 Main Street, E62-516

Cambridge, MA 02142

and NBER

jjdoyle@mit.edu 


\section{Introduction}

What types of physicians achieve better health outcomes for their patients? The answer is clearly important to patients choosing physicians, which is why healthcare providers, payers, and state-licensing organizations provide information on physician characteristics such as specialty, medical training, sex, and years of experience. The answer is also important to providers when making hiring decisions and determining the relative sizes of their departments. Payers would also like to understand the types of physicians that provide higher-quality care when choosing provider networks and compensation models. Indeed, most leading ideas for payment reforms revolve around "paying for quality" to replace the current method of "paying for quantity" of care. Related, public policies affect physician characteristics directly, such as concentrating care at regional providers to increase physician experience. For all of these reasons, it would be useful to know the effectiveness of different types of physicians.

A prime example is the case of specialists. A robust finding is that specialists provide more intensive treatments, but evidence on improved patient health has been mixed. Steinwald et al. 2019 summarize the evidence and find that a 1 percentage-point increase in the proportion of physicians who provide primary care as opposed to specialist care would result in $\$ 100$ billion in healthcare savings over 10 years without any tradeoff in quality of care. As a result, health policy advocates call for policies that reduce the disparity in pay between specialists and general practitioners and subsidize the choice to become a general practitioner in the first place Basu et al., 2019, Levine et al., 2019, Steinwald et al., 2019].

Despite this interest in the ability to characterize the types of physicians that achieve better health outcomes, there are concerns that endogenous patient selection confounds comparisons across physicians. For example, patients assigned to specialists appear healthier than patients assigned to internal-medicine physicians, consistent with younger, healthier patients being more suitable for invasive procedures. Another confounding factor is that different types of physicians are matched to work environments that can differ with regard 
to complementary physical and human capital.

The aim of this paper is to circumvent these estimation problems for a subset of patients - those who have health shocks and are admitted to the hospital via the emergency department. Recent studies find that physician scheduling is effectively random within a given hospital across short periods of time Chan, forthcoming, Silver, 2020, Tsugawa et al. 2017c . The causal framework developed below uses this idea to compare patients exposed to different combinations of physicians available on the day they enter the hospital. This empirical strategy provides direct evidence on the implications of changing the mix of physicians available (e.g. favoring the training and hiring of more general practitioners over specialists) and indirect evidence on the returns to being treated by different types of physicians.

One innovation in the paper is the construction of a proxy for physician availability from claims data. In particular, 100\% Medicare inpatient claims data are used to trace out which physicians are admitting Medicare patients on any given date. Measures of the types of physicians available are then constructed using "leave-out measures" that are not affected by the physician assigned to any patient whose outcomes are studied.

The main analysis focuses on heart failure patients, the most common diagnosis for inpatient admission in the US Hall et al. . $^{1}$ The ubiquity of the condition helps insure against concerns that physician schedules are set to match the types of patients arriving on a given date or that the admission of a given patient changes the mix of physicians available (through summoning an on-call physician for an unusual case, for example). In fact, internal medicine physicians, not cardiologists, usually treat heart-failure patients, and the analysis will test whether patients would benefit from greater involvement by cardiologists.

The analysis considers the following physician characteristics: physician specialty, medical school rankings, sex, years of experience, and patient volume. The results suggest that within a given hospital, heart failure patients exposed to more cardiologists are more likely

\footnotetext{
${ }^{1}$ Heart failure is the most common among the disaggregated conditions considered. Similarly, heart failure is the most common primary 3-digit ICD-9 diagnosis code for patients in fee-for-service Medicare studied here.
} 
to survive to one year following the emergency admission. The results also show that having more available cardiologists is strongly related to both treatment by a cardiologist and more invasive procedures, and the higher level of treatment intensity appears to be worth the extra expense.

The other physician characteristics studied have more muted effects. One exception is physician experience: when the mix of available physicians have a higher volume of heartfailure patients over the prior year, patients have somewhat lower mortality. While these other physician characteristics may relate to quality in general, the empirical strategy compares different types of physicians within the same hospital. The comparison of specialists and non-specialists is particularly relevant because it mimics the triage of patients across hospital departments such as cardiology and internal medicine units, and it can inform policies aimed at reducing the use of specialists in favor of lower-cost general practitioners.

The remainder of the paper is organized as follows. Section 2 places the research in the context of previous literature that relates physician characteristics to patient health outcomes. Section 3 discusses the economic framework, empirical model, and data used to estimate it. Section 4 presents the main results, and Section 5 concludes.

\section{Background}

This section reviews the literature that describes the relationship between the type of physician treating patients and the cost and quality of care provided. The main results relate to returns to specialty care, and this aspect of the literature is described in more detail. Other physician characteristics studied include volume and experience, physician training and practice styles, and physician sex. The empirical literature describing physician scheduling is then described, as it forms the basis of the empirical strategy. 


\subsection{Measuring Returns to Physician Specialty}

\subsubsection{Potential mechanisms for returns to specialty care}

Specialization can improve productivity through greater experience and training. Currie and Macleod 2017 develop a model to assess physician productivity along two dimensions: decision making and procedural skill, and Abaluck et al. [2016] and Chan et al. 2020 highlight the quality of diagnostic skill that varies across physicians. Specialization of training and practice may improve performance along both of these dimensions. For example, the idea that specialists have more current information was highlighted by Ayanian et al. [1994. They surveyed cardiologists, internists and family practitioners and found that cardiologists were better informed than other physicians with respect to recent evidence on the effectiveness of different drug therapies for acute myocardial infarction (AMI) patients.

Further, the typical tradeoff associated with specialization is between the greater skill of the specialist against the cost of coordination Becker and Murphy, 1992, Meltzer, 2001. In the current context, the assignment of a specialist as an attending physician would increase the use of specialists but would actually reduce the need for coordination because the specialist is treating the patient directly.

When estimating returns to care, it is also well known that specialists are associated with greater levels of treatment intensity. A question is whether any improved outcomes found are worth the extra expense. In the end, the comparison of outcome and cost differences is an empirical question. This paper considers one (particularly costly) element: returns to specialty care during health emergencies.

\subsubsection{Patient-level evidence}

There is a large number of studies that compare patients treated by specialists vs. nonspecialists. Hartz and James 2006 reviewed the literature on the effects of specialist care for AMI patients among articles written between 1990 and 2003. The review shows that spe- 
cialists tend to provide more care and are often found to be associated with lower mortality, although there is mixed evidence on the mortality relationship. The literature makes clear that specialists treat younger, healthier patients compared to general practitioners, which can confound comparisons. The review notes that different practice environments can also make comparisons difficult.

Go et al. 2000 provide another review for treatment of coronary disease and heart failure. They conclude that cardiologists provide more evidence-based care and "probably better outcomes". Harrold et al. [1999] offer a third review of the literature from 1981-1998. Specialists again are found to be more knowledgeable, as they are more likely to use medicines shown to be effective and comply with routine guidelines. They also employ more diagnostic tests, procedures, and are associated with longer hospital stays. This review argues that health outcomes are less likely to be studied, but better outcomes tend to be found for patients of specialists among AMI, stroke and asthma patients. The reviews caution that these studies are often small in scale, and there remain concerns over selection bias.

When mortality differences are found, they tend to be large in magnitude. In a relatively large observational study, Zaman et al. 2015 studied 85,000 patients in England and Wales with non-ST elevation myocardial infarction and controlled for patient characteristics in a multivariate analysis. They found that cardiologists' patients had $42 \%$ lower mortality for those aged under 65 and 13\% lower mortality for those aged 85 and over. Another relatively large study by Casale et al. [1998] studied 30,715 AMI patients in Pennsylvania and controlled for patient, hospital, and payer characteristics. They found $17 \%$ lower mortality for those treated by cardiologists. Similarly, Jollis et al. 1996 studied Medicare patients in 1992 admitted for AMI. Patients admitted by cardiologists were found to be healthier at admission, were more likely to be prescribed effective drug therapies such as beta-blockers, and underwent cardiac procedures at a much higher rate (e.g. $49 \%$ with angiography vs. $30 \%$ for internal medicine physicians and $21 \%$ for other general practitioners). They were also $13 \%$ less likely to die within one year compared to a general practitioner. Importantly 
for this paper, (1) results were similar whether they used the detailed controls contained in the Cardiovascular Cooperative Project or a larger sample of claims data similar to the data used here, and (2) in the vast majority of cases the admitting physician is the same as the attending physician ("the clinician who is primarily and largely responsible for the care of the patient from the beginning of the hospital episode"), a feature used in the empirical strategy described below.

Similar results have been found for heart failure episodes, often using smaller samples and selection on observables for identification. Uthamalingam et al. 2015 studied 496 patients in New Hampshire and relied on a rich set of controls. They found that heart failure patients treated by cardiologists received more guideline-adherent care, had lower readmission rates (16\% vs. $40 \%$ ), and had lower mortality at 6 months (6\% vs. $11 \%$ ). Kondo et al. 2018 studied acute heart failure patients in Japan who entered the hospital via the emergency department. Using propensity-score matching among 932 patients, the authors found that ED patients treated by cardiologists received more intensive treatment compared to emergency physicians, although they found little difference in in-hospital mortality.

Other conditions have also been studied. Gillum and Johnston [2008] studied stroke patients at 115 academic medical centers from 1997-1999 and found that patients assigned to neurologists had lower in-hospital mortality rates compared to those assigned to general practitioners ( $4.6 \%$ vs. $9.5 \%$ ). They note that this could be due to selection bias and compare patients across hospitals, finding no difference in mortality with respect to the rates of neurologist assignment at those hospitals. Goldstein et al. 2003 carried out the VA Stroke Study, involving 1073 patients admitted with ischemic stroke and found that those who received care from a neurologist received substantially more tests and had lower inpatient mortality (5.6\% vs. 13.5\%); controlling for (potentially endogenous) measures of stroke severity and comorbidities explained about half of the mortality gap. Meanwhile, Mitchell et al. [1996 analyzed stroke patients in Medicare in 1991. Neurologists were found to order more tests, such as CT scans and brain MRIs, had higher overall costs, and 90-day 
mortality was significantly lower for patients of neurologists compared to family practitioners, internists, and patients cared for by a combination of a neurologist and an internist - the group with the highest costs. The role of pulmonologists in the care of pneumonia patients has received relatively less attention. Lin et al. 2008] grouped pulmonary and critical care medicine specialists in Taiwan and found mortality rates were lower for those assigned a specialist (9.8\% vs. $15.3 \%)$.

In summary, patient-level analyses show that specialist usage is associated with higher quantities of care, and specialists tend to have better information about the relative effectiveness of different types of therapies. There is mixed evidence on outcomes, but most larger studies find that specialists are associated with better outcomes. The primary literature reviews caution that selection bias can contaminate these comparisons, however, and call for empirical strategies that use quasi-experimental variation in specialist treatment to estimate returns to their care.

\subsubsection{Evidence from regional variation}

Another approach to measure returns to specialization relies on the wide regional variation

in the use of specialists in the U.S. Baicker and Chandra 2004a bind that markets that use specialists at higher rates have higher costs, including greater intensive-care unit services and more doctors seen in the last six months of life. Higher usage is also associated with lower adherence to evidence-based care and little difference in patient satisfaction and mortality. As a result, they argue that specialists may not be worth their extra expense.

Skinner et al. 2006] study changes in the number of physicians treating heart attack patients-a measure related to the reliance on specialists-within health referral regions between 1986 and 2002. The areas with the largest increases in the number of physicians treating a patient were associated with higher spending but smaller survival gains: $8.7 \%$ in the top quartile vs. $11.2 \%$ in the lowest quartile. Agha et al. [2019] focus on patient movers to measure the extent to which treatment in areas with different levels of fragmentation 
affect healthcare and health outcomes. They find that patients with chronic conditions who move to areas with more specialist care had higher levels of utilization. They provide some evidence of greater guideline-adherent care among patients with diabetes, such as biometric tracking. Chernew et al. 2009] also used Medicare data to show that areas with more primary care physicians have lower levels of spending, but there was little relationship with spending growth between 1995 and 2005.

Together these studies find that areas with more specialists have higher costs, lower procedural-quality measures, and little difference in health outcomes. When within-area variation in specialists is explored, there is mixed evidence of an increase in costs, but little relation with procedural quality and health outcomes. These regional comparisons also tend to relate to differences in the treatment of chronic conditions, whereas the analysis here will speak more directly to effects of specialist usage following a health shock.

\subsection{Other Physician Characteristics}

\subsubsection{Volume and experience}

There is also a vast literature documenting a volume-outcome relationship: physicians that treat more patients tend to have better health outcomes Chandra and Staiger, 2007, Shahian and Normand, 2003, Birkmeyer et al., 2003. However, there is a concern that selection bias can inflate this correlation beyond the causal effects from skill development. Archampong et al. 2012 review evidence for the role of volume and specialty in the treatment of colorectal cancer and conclude that because it is difficult to randomize these characteristics of physicians, there continues to be a need for quasi-experimental evidence on these relationships.

Of particular concern is that high-volume physicians treat different types of patients compared to those who treat fewer. For example, if a physician rarely treats a particular type of patient, then the fact that a given patient is treated by that physician may mean that there is something special about the circumstances of the match, such as the lack of time to transport the patient or call in a physician who is more suited to the case. 


\subsubsection{Physician training and practice styles}

There is also an interest in whether physician training, including medical school and residency quality, leads to differences in practice styles and patient health outcomes. It is well established that physicians vary widely in their treatment patterns, even within small areas Glover, 1938, Wennberg and Gittelsohn, 1973, and this variation may point to significant waste Fisher et al. 2003. Tsugawa et al. 2017c studied Medicare data from 2011-2014 and found that within-hospital variation in treatment intensity is greater than the much-studied variation across hospitals. They also found that higher-spending physicians did not have better outcomes than those with lower levels of spending, pointing to a potential source of wasteful spending. One concern when using this variation to estimate returns to spending is that higher-spending may be related to physician skill [Doyle et al., 2010]. Chan et al. 2020 find that in the case of radiologists, treatment intensity is likely correlated with physician skill, which implies that instrumental-variable estimates using this type of variation may be biased due to violations of the exclusion restriction and monotonicity assumptions.

When researchers investigate physician characteristics that are related to treatment intensity, however, relatively little has been found Berndt et al., 2015, Epstein and Nicholson, 2009, Cutler et al., 2019, Chan, forthcoming). This includes little correlation with the medical school attended. Meanwhile, when medical school quality is examined more directly, the typical result is that US trained physicians achieve better outcomes compared to non-US trained physicians, although the evidence here is mixed Ko et al., 2005, Tsugawa et al., 2017b, Zaheer et al., 2017.

\subsubsection{Physician sex}

One characteristic that is often observed in data but not studied as extensively as characteristics such as specialty and patient volume is the sex of the physician Berthold et al., 2008. Treatment by a female physician has been found to be positively correlated with higher-quality care. Wallis et al. 2017 studied 3314 physicians in Ontario, Canada and 
found that female surgeons have a $12 \%$ lower 30 -day mortality rate. Tsugawa et al. 2017a studied hospitalists and found that patients treated by female physicians have a $4 \%$ lower 30-day readmission rate and a $4 \%$ lower 30-day mortality rate.

There is also interest in the gender concordance of physicians and patients. Greenwood et al. 2018] focused on heart-attack patients in Florida and found that patients assigned female physicians had lower in-hospital mortality rates compared to those assigned to male physicians, especially when the patient was female. Roter et al. [2002] reviewed the literature and found that one potential explanation is that female physicians have different communication styles compared to male physicians.

\subsection{Physician Availability}

One of the main assumptions underlying the empirical strategy is that physician availability is exogenous within a hospital, especially for the treatment of patients who enter the hospital via the emergency room over short periods of time. While there is triage of patients across areas of the hospital, for example admission to a cardiology unit versus an internal medicine unit, the staffing of those units vary from day to day in ways that are arguably unrelated to patient characteristics after controlling for day of the week and season. Previous papers have looked within a given institution, or within a given specialty, and noted that the scheduling of physicians is not geared toward expected patient characteristics nor co-worker characteristics Chan, forthcoming, Silver, 2020, Tsugawa et al., 2017b. This paper studies a common health condition and uses the idea of non-targeted scheduling in an attempt to exploit plausibly exogenous variation in the the availability of different types of physicians, as described in more detail in the next section. 


\section{Empirical Framework and Data Description}

This section describes the empirical framework and the data used to clarify the empirical question and approach.

\subsection{Health production function and empirical model}

The main question in the paper is what types of physician characteristics improve patient health. Consider a simple health production function that relates patient health to the labor and capital that is used to treat a patient:

$$
H=f(L, K ; X, E)
$$

where $\mathrm{L}$ is a vector of different forms of labor, including different types of physicians and complementary labor such as nurses and assistants. $\mathrm{K}$ is a vector of capital employed, such as imaging capabilities and lab quality. X represents patient characteristics to allow the production function to vary by patient illness severity, for example. E represents characteristics of the environment, such as congestion, that can alter the way labor and capital translate into health outcomes.

The empirical model takes the following form for patient i treated in hospital h on date d during quarter $q(d)$ on day-of-the-week dow $(d)$ :

$$
Y_{i h d}=\beta_{0}+\beta_{1} P_{h d}+\beta_{2} X_{i}+\beta_{3} E_{h d}+\lambda_{h q(d) d o w(d)}+\epsilon_{i h d}
$$

The main health outcome studied is 1-year mortality, and similar models will be employed to study effects on healthcare utilization. $\mathrm{P}$ is the vector of characteristics that describe the set of physicians available to treat a patient on the admission date, such as the number of cardiologists available. This estimation strategy traces out effects as the types of available physicians changes and provides transparent estimates of the relationship between the mix 
of available physicians and health outcomes ${ }^{2}$

$\mathrm{X}$ represents patient controls, including indicators for patient age, race, sex, and quintile of one-year lagged spending paid to inpatient plus outpatient facilities to reflect the underlying health of patients prior to the health emergencies studied here. To the extent that physician characteristics are effectively random, the main estimates should not be affected regardless of whether patient controls are included in the model. The analysis will also test whether estimates vary with patient characteristics.

E represents characteristics of the environment, namely indicators for the number of other patients admitted on the same day and the number of physicians observed on the same day, which may be important given the empirical strategy. When controlling for the number of physicians available, examining the effect of the number of a particular type of physician, say cardiologists or male physicians, is akin to considering the change in the mix of physicians available holding the number of physicians constant.

Other features of the health production function include complementary labor and capital. The effects of these factors are interesting in their own right, but the empirical approach to isolate the effects of physician characteristics will compare patients within cells where these additional influences are assumed to be absorbed by the set of fixed effects defined by hospital $\mathrm{x}$ quarter $\mathrm{x}$ day-of-week cells. For example, this within-cell variation compares patients entering the same hospital on a Thursday in the spring of 2007. Models using hospital $\mathrm{x}$ month $\mathrm{x}$ day-of-week cells are also reported. The within-cell variation also attempts to absorb unobserved differences in patients arriving at different times of the year or across

\footnotetext{
${ }^{2}$ An alternative estimation strategy would be to estimate a mortality model with fixed effects for each physician and then relate those effects to physician characteristics. A key limitation with this approach is a lack of precision, which leads researchers to (1) limit the estimates to physicians with more than a minimum number of patients and (2) shrink estimates to account for the noise, which is larger for physicians with fewer patients. The number of observations per physician is endogenous-the well-known volume-outcome relationship described in this paper-and these corrections impose additional structure that introduces new bias concerns. When mapping characteristics to outcomes is the goal, the current approach retains more data, which helps with precision and sample-selection-bias concerns, and allows physician effects to vary over time. In any event, in the current context when limiting the sample to focus on plausibly exogenous variation, the average number of heart failure patients per physician ID is 6 , which is below traditional benchmarks for estimating such fixed effects.
} 
days of the week.

In terms of interpretation, the inclusion of these fixed effects alter the question from whether physician training, say, matters at all to whether it matters across physicians within a given hospital. For example, physicians who went to different medical schools that vary significantly in quality but work at the same hospital may have similar outcomes because they came through the same screen of the hospital's hiring committees. As a result, some characteristics may matter less within a hospital relative to across hospitals. Instead, the estimates speak to the debate on the effectiveness of different types of physicians controlling for their practice environment and directly inform questions regarding the optimal mix of physicians that could be available to treat patients in a given time and place.

One limitation of the empirical strategy is that data on the availability and characteristics of nurses are not available. Instead, the empirical strategy relies on the literature reviewed above that suggests that complementary labor availability is not correlated with physician availability when single institutions are studied, which is consistent with anecdotal evidence that nurse schedules are set independently from physician schedules outside of surgical teams. To the extent that in some contexts physicians work in teams with complementary labor, then any impact on outcomes found would stem the bundled characteristics of the teams associated with treatment by particular types of physicians.

Welfare implications depend on findings related to both health and healthcare costs. This paper studies patient mortality as an objective, but incomplete, measure of patient health. Nevertheless, when changes in mortality are found, they tend to dominate welfare comparisons given the high value of statistical life. In terms of costs, results below will show estimates of equation (2) where the outcomes are treatment intensity at the time of the health shock and over the following year. The ratio of the effects of physician characteristics available on mortality to the effects on treatment intensity provides an estimate of the local average treatment effect (LATE) of treatment intensity on mortality. This estimate would be valid under the strong assumption that the only way physician availability measures 
affect mortality stems from changes in the treatment intensity $\left.\right|^{3}$ Further, this change in mortality related to the change in treatment at each level of physician availability can be used to estimate marginal treatment effects Heckman and Vytlacil, 2005. While these instrumental-variable estimates are useful for context, the reduced-form estimates of the effects of availability directly on health and treatment intensity can inform polices that affect that types of physicians that are available at the time of a health shock.

Standard errors are clustered at the hospital level to take into account correlated errors across patients within institutions. The leave-out measures of physician characteristics are generated from the data; when standard errors are bootstrapped to take into account the noise generated from constructing them, they are slightly smaller than the asymptotic standard errors reported below. In that limited sense, the reported standard errors are relatively robust and conservative compared to bootstrapped standard errors.

\subsection{Data Description}

The analysis uses Medicare inpatient and outpatient claims data between 1998 and 2012. The main analysis focuses on patients whose primary diagnosis is heart failure $4^{4 n}$ terms of the hospital setting, the claims data include an identifier for the hospital and the admission and discharge dates. The data have been linked by the Centers of Medicare and Medicaid Services (CMS) to vital statistics data to provide mortality outcomes at different time horizons.

Treatment intensity can be measured by procedures performed, as well as Medicare expenditures and hospital (list) charges. Three identifiers for physicians who treated the patient are present in the data: the attending physician responsible for the care of the patient, which is always recorded, as well as an operating physician and an "other" physician that are sometimes listed; these latter two categories represent physicians who have substantial billing associated with the episode, when applicable.

\footnotetext{
${ }^{3}$ Interpretation of the estimates as a LATE also requires a monotonoicity assumption that the availability of more cardiologists, say, does not reduce the likelihood that a patient would be treated by one Imbens and Angrist, 1994, Chaisemartin, 2017.

${ }^{4}$ The primary diagnosis has a 3-digit ICD9 code of 428.
} 
Patient characteristics include age, race, sex and Medicare facility spending such as previous inpatient admissions and office visits in the calendar year prior to the index admission-a measure of health that is highly predictive of mortality.

\subsubsection{Measuring physician availability}

Hospital scheduling data are not available in this nationwide dataset. Instead, one of the innovations of the current paper is the construction of proxy measures for the number of different types of physicians available in a given hospital on any given date using the $100 \%$ inpatient claims from CMS. The proxies are based on the attending physicians who admitted Medicare patients on those dates (including patients with diagnoses other than heart failure).

These are proxy measures because physicians may be present on a given date but do not admit a Medicare patient that day. If the noise of the proxy measurement approximates classical measurement error, the estimated coefficients will be biased toward zero. To explore the influence of noise on the results further, the analysis will test for robustness when examining different dates when the proxy is thought to vary in quality. In addition, under strong assumptions, the proxies for physician characteristics can be used as instruments to test the effects of care provided by a particular type of physician.

A primary concern with the use of claims data to identify physicians available on a given date is that the measurement is a function of how many other patients are admitted on that date: a level of activity that can have its own impact on treatment intensity and ultimately on patient outcomes. As a result, the empirical model includes flexible controls for the level of activity. Specifically, the models include a set of indicators for the number of patients and the number of physicians observed on a given date to nonparametrically control for the relationship between these activity levels and outcomes. While a key concern at the outset, in this context the estimates are not sensitive to the inclusion of these flexible controls or when other robustness tests are performed.

When calculating the characteristics of physicians observed on the date of admission, the 
patient's own attending physician will affect that calculation, but that physician's characteristics may be endogenous. Another innovation in the use of claims data to exploit plausibly exogenous physician availability is a sample restriction: the sample used in the main analysis is restricted to patients assigned to physicians who admitted at least one other patient on the same date. This allows the availability measures to be constructed based on the characteristics of physicians assigned to all other patients admitted on the same date: leave-out measures that are not influenced by endogenous physician assignment. For example, the calculation of the number of specialists available on a given date is unchanged regardless of whether the patient was assigned to a specialist or not. The resulting estimates will apply to physicians who admitted at least one other Medicare patient on the same date.

Another endogeneity concern is that the physician could have been called into the hospital to treat a particular patient and then subsequently treated another patient. Following discussions with physicians, it seems that this is unlikely in the case of very common diagnoses where the staff in the hospital are expected to treat those patients without calling in a physician. The main analysis focuses on heart failure patients. This is the most common 3-digit ICD-9 diagnosis for admission via the emergency room in Medicare claims data by a fairly wide margin. In 2007 - the middle of the sample period for the analysis - 476,137 patients met this definition compared to 384,266 for the next-most-common diagnosis: pneumonia. The analysis below will also examine whether observable characteristics of patients are balanced with respect to measures of physician availability as a check on the plausibility of the exogeneity assumption.

\subsubsection{Physician characteristics}

The claims data include identifiers (UPIN and NPI) for the attending physician, an operating physician for the principal procedure performed if applicable, and a third field for "other physician" who generated substantial claims during the hospital stay when applicable. These identifiers were linked to the American Medical Association's Masterfile, which lists the 
physician's year of graduation, sex, primary and secondary specialty, and medical school $5^{5}$ The medical school IDs have been matched to the US News and World Report's medical school rankings for 2004, including measures for the ranking in primary care instruction as well as a separate ranking for research. A related characteristic is an indicator for whether the physician graduated from a U.S. medical school. Physician experience is measured using the $100 \%$ inpatient claims data and calculated as the number of heart failure patients the physician served as the attending physician over the prior year.

\subsection{Analysis Sample}

A number of sample restrictions are imposed to focus on the natural experiment described above. First, in order to measure patient characteristics prior to and after the beneficiary's first heart failure admission in the Medicare data, the sample is restricted to patients who have been continuously enrolled in fee-for-service Medicare, as opposed to the approximately $20 \%$ of beneficiaries who enroll in Medicare Advantage over this time period and whose data are either not available or thought to be less reliable. Second, to avoid endogenous assignment due to scheduled admissions, the sample is restricted to patients who are admitted via the emergency room. Third, for an uncensored measure of 1-year mortality and 1-year lagged measures of patient health the empirical model is estimated using data from 19992011. Fourth, to focus on larger hospitals that allow for more precise estimates and where the measures of physician availability are more stable, hospitals with fewer than 100 heart failure patients over the entire sample period are excluded. Fifth, to examine patients at higher risk of invasive treatment, the main analysis studies patients who are less than 90 years old, although results are similar without this restriction. Last, a small number of observations are also excluded due to missing observations. The resulting dataset includes

\footnotetext{
${ }^{5}$ Specialty types are defined as being indicated as either a primary or secondary specialty. Approximately $90 \%$ of the specialists are defined due to their primary specialty. $15 \%$ of attending physicians either did not list a specialty or did not match to the AMA Masterfile. These physicians are assumed to be non-specialists, and results predicting specialist usage are nearly identical when patients assigned to these physicians are excluded.
} 
909,083 heart failure patients treated at 2,760 hospitals. The number of unique attending physician identifiers is $144,355.6$

The analysis sample is much smaller than the full sample in large part due to the restriction to patients assigned to physicians observed to be the attending physician for at least two patients on any given admission date in the 100\% Medicare inpatient claims data (see Table A1). The results will apply to patients whose attending physicians are relatively busy, although robustness to different levels of activity are shown below.

The analysis sample is broadly similar to the wider set of heart failure patients (Table A2). The analysis sample is somewhat younger (78 vs. 80 years old), similar in terms of race and ethnicity and more likely to be male (46\% vs. $43 \%$ ). One-year lagged spending is slightly higher in the analysis sample, and the mortality rate is slightly smaller. In terms of physician characteristics, more physicians are observed in the analysis sample: 16 per day compared to 13 in the full sample. That said, the composition of the physicians is similar, with the number of physicians who attended a top 50 medical school (out of 126 schools) averaging $28 \%$ in both samples, and the fraction male averaging $82 \%$ in both samples. The analysis sample has slightly higher rates of cardiologist availability, averaging $12.7 \%$ in the analysis sample and $12.1 \%$ in the full sample.

Figure 1 explores the amount of variation in the number of cardiologists observed after the data have been de-meaned at the hospital-quarter-day of week level. On average, there are 2 cardiologists available in the analysis sample, and Figure 1 shows that this ranges from about 1 less to 1.5 more cardiologists in the heart of the data. Similarly, Table A3 reports the amount of within-cell variation in the measures of physician characteristics observed. The overall standard deviation in the number of cardiologists is 2.5 , and when this measure is demeaned within these cells, the resulting standard deviation is only 1.0. Similarly, across the attending physicians available on a given date, the average volume of heart failure patients

\footnotetext{
${ }^{6}$ The number of attending physicians identifiers is defined by the number of unique UPIN identifiers when available, and NPI identifiers otherwise. It is possible that the same physician billed under more than one UPIN or NPI.
} 
over the prior year has a standard deviation of 6.91 patients, but this falls to 2.6 within the hospital-quarter-day of week cells. In an effort to exploit plausibly exogenous variation in the availability of different types of physicians within hospitals over short periods of time, the tradeoff is the use of less variation at the cost of less-precise estimates.

\section{Results}

\subsection{Plausibility}

Selection bias may confound comparisons of patients assigned to different types of physicians, and a key identifying assumption is that the mix of physicians available to treat a patient on the date of admission is exogenous. As a first look at these concerns, Table 1 compares observable characteristics of patients across (1) the type of attending physician assigned to the patient to consider the potential role for selection bias, and (2) across dates that differ with respect to the availability of different types of physicians as a balance check. The main results focus on specialists, so Table 1 makes these comparisons in relation to the use or availability of cardiologists.

Column (1) is the sample mean among patients assigned to attending physicians other than a cardiologist, while Column (2) is this mean plus the estimated coefficient on an indicator for cardiologist assignment from a linear regression that predicts each characteristic and includes hospital $\mathrm{x}$ quarter $\mathrm{x}$ day-of-week fixed effects to focus on the same within-cell comparisons as the other comparisons in the paper.7 One of the largest differences is the sex of the patient, where patients assigned to a cardiologists are 11 percentage more likely to be male (55\% vs. 44\%). Patients assigned to a cardiologist tend to be one year younger than those assigned to a general practitioner (77.4 vs. 78.4 years old). There are some differences in terms of race: $7 \%$ of patients assigned to a cardiologist are African American compared to $12 \%$ of patients assigned to a non-cardiologist. One-year lagged spending on both inpatient

\footnotetext{
${ }^{7}$ Similar differences are found for the subset of patients assigned to a cardiologist or a general practitioner.
} 
and outpatient facility claims is found to be lower for those assigned to a cardiologist $(\$ 11,900$ vs. $\$ 13,300)$, an $11 \%$ difference. These comparisons show that cardiologists treat somewhat healthier patients, consistent with the prior literature.

The number of physicians admitting patients, and the number of patients admitted, on the same date are similar across the two groups. Meanwhile, patients assigned to a cardiologist are more likely to enter on dates when there are more cardiologists (2.2 vs. 1.6), which previews the result that the mix of physicians available impacts the types of physicians that treat the patient.

Columns (3) and (4) compare patients who arrive on dates that vary by the number of cardiologists available as a balance check. Specifically, a low-cardiologist date is one when the number of cardiologists observed in the hospital is less than the mean within the hospital $\mathrm{x}$ quarter $\mathrm{x}$ day-of-week cell. Column (4) is analogous to Column (2): the low-cardiologist-date mean plus the coefficient from an indicator that the date had a high number of cardiologists available, controlling for the cell fixed effects. Observable differences are considerably smaller, although many are statistically significantly different due in part to the large sample size. Most striking is that in contrast to the assignment of cardiologists, the fraction of patients who are male is remarkably similar across dates when cardiologist availability differs (45\% vs. $46 \%$ ). The average age (78.3 vs. 78.2$)$, the fraction black (11\% vs. $10 \%$ ), and 1-year lagged spending (\$13,000 vs. 12,900) are all notably similar across the different types of dates. The similarity in observable characteristics is consistent with the exogeneity of the number of cardiologists observed within a hospital x quarter x day-of-week cell due to effectively random variation from physician scheduling.

While the patient characteristics are similar across these types of dates, the comparison introduces a difference in the practice environment: days that have a high number of cardiologists observed also have a higher number of physicians observed overall (15.7 vs. 13.6) and the number of patients is also higher (22.0 vs. 19.6). The number of cardiologists available is higher (3.11 vs. 1.21), by construction. More patients admitted on the same date allows 
the proxy to measure more physicians. Busier days, albeit with more physicians, can impact treatment intensity and health outcomes directly, which motivates the use of flexible controls for these environmental characteristics as well as robustness checks. While such differences represent a key concern when using claims data to proxy for physician availability, in this context such differences in activity do not appear to be driving the main results.

\subsection{Specialist Availability and Mortality}

The main physician characteristic that is found to be related to survival is the availability of cardiologists. This is particularly policy relevant for within-hospital comparisons given the triage of patients between cardiac and internal-medicine units. It also informs the policies aimed at increasing reliance on lower-cost general practitioners, at least along the dimension of survival for these emergency patients.

Figure 2 plots the main result. The x-axis reports the number of cardiologists observed to be available ranging from from 0 to 4-or-more 8 There are two outcomes shown. The blue line with the circular markers reports the relationship between the number of available cardiologists and predicted 1-year mortality, where predicted 1-year mortality was estimated using a probit model and the full set of patient controls. The orange line with square markers is actual 1-year mortality. The relationships between these outcomes and cardiologist availability reported in the figure were estimated using a linear regression model that included hospital $\mathrm{x}$ quarter $\mathrm{x}$ day-of-week fixed effects along with indicators for the number of available cardiologists. Results that incorporate controls will be reported below.

This figure shows that mortality falls with each level of available cardiologists. Compared to when there are zero cardiologists observed available, having 4 or more cardiologists is associated with a 2 percentage-point reduction in mortality (or $6 \%$ of the mean). In contrast, predicted mortality is relatively unrelated to the number of cardiologists available. Compared to zero cardiologists available, when there are 4 or more cardiologists the patients are

\footnotetext{
${ }^{8}$ Figure A1 shows the distribution of the number of cardiologists observed; each of these physicianavailability categories includes $10 \%$ or more of the data).
} 
only slightly healthier: a coefficient of -0.002 , which is statistically significant but arguably not economically significant. The other coefficients are even smaller and not statistically significant.

To examine the effects of cardiologist availability across a wide number of analyses, the remaining Tables compare patients across three levels of cardiologist availability: the $34 \%$ of the sample with zero observed cardiologists, the $22 \%$ with one available cardiologist (a measure of the extensive margin) and the remaining $44 \%$ with 2 or more available cardiologists.

Table 2 reports these results. First, columns (1) to (4) report estimates from a regression of mortality on whether the patient was assigned a cardiologist as an attending physician or was treated by a cardiologist at all, including those undergoing cardiac operations. Comparing patients in the same hospital, month, and day-of-week cells, 1-year mortality is substantially lower for those treated by a cardiologist (approximately 30\% lower than the mean). When informative controls (especially age and lagged spending) are added to the model, patients assigned to cardiologists continue to have lower mortality: 8 percentage points lower, or $24 \%$ lower than the mean. There remain concerns that patients differ in terms of unobserved characteristics such that selection bias may inflate these coefficients.

The table further examines how mortality falls with the availability of cardiologists. In models similar to those shown in Figure 2, mortality is regressed on indicators for the level of cardiologist availability. A regressor for the number of other specialists is also included (1) to hold constant both the number of other specialists and (in most models) the number of physicians in total such that residual variation in the number of cardiologists stems from a policy-relevant reduction in the number of general practitioners, and (2) as a specification check on whether unrelated specialists are related to mortality for heart failure patients controlling for the number of cardiologists, which could happen if specialist availability were related to unobserved differences in patient mix or hospital staffing.

Column (5) reports results with no controls other than the fixed effects for the hospital $\mathrm{x}$ quarter $\mathrm{x}$ day-of-week cells. The estimates show that moving from zero cardiologists 
observed to one cardiologist observed lowers mortality by 0.7 percentage points. Moving from zero cardiologists to two or more cardiologists roughly doubles the effect: a 1.3 percentagepoint reduction in mortality. ${ }^{9}$ To compare these magnitudes with those in Columns (1)-(4), the relationship between cardiologist availability and direct treatment by a cardiologist is explored below. Meanwhile, the number of other specialists is largely unrelated to 1-year mortality controlling for the number of cardiologists.

The next column shows results when the number of physicians and the number of patients observed are controlled in a flexible way. This changes the interpretation from the number of cardiologists available to the number of cardiologists available conditional on the number of physicians available - in essence considering the change in the mix of physicians rather than the levels. Further, given that the proxy for availability is a function of the number of patients observed, this is a potentially important control for the analysis. The point estimates increase only slightly in magnitude when they are included. In the end, while the idea that the proxy is a function of how busy the hospital is continues to be a concern more generally, in this context the results are not sensitive to controlling flexibly for these environment variables.

Column (7) adds controls for patient characteristics described above. When they are added, the point estimates decline slightly, although the estimates are not statistically distinguishable from the model with no controls. In particular, increasing from zero to one cardiologist observed in the data results in a 0.65 percentage-point reduction in mortality, and increasing from zero to two-or-more cardiologists results in a 1.2 percentage-point reduction in mortality. The next column shows that these coefficients are barely affected when controlling for other physician characteristics, which are explored in more detail below.

Columns (9) and (10) replace hospital x quarter $\mathrm{x}$ day-of-week fixed effects with the more stringent hospital x month x day-of-week fixed effects. These cells are much smaller and the standard errors typically double. Nevertheless, the point estimates are notably

\footnotetext{
${ }^{9}$ Appendix Table A4 shows that these results appear at 30 days as well.
} 
similar, especially the estimate of increasing from zero to two or more cardiologists. While this level of within-cell variation does not support precise estimates, it is reassuring that similar estimates are found when comparing patients that are even more likely to be similar to one another: those who enter the same hospital on the same day of the week in the same month of the year (e.g. Thursdays in April 2007).

\subsection{Other Physician Characteristics and Mortality}

Table 3 reports the results describing the relationship between the vector of physician characteristics and 1-year mortality. Column (1) displays estimates when each physician-availability characteristic is estimated separately. These estimated effects will include the overlap in the measures, while column (2) reports results where the full vector of characteristics is included in the same regression.

Similar to the previous subsection, the first row reports the linear relationship between the number of cardiologists available and mortality: a two standard deviation increase in the within-cell variation is approximately 2 cardiologists (Figure 1), and Table 3 shows that this is associated with a 0.7 percentage-point reduction in mortality. The magnitude is remarkably similar when the model only includes the number of cardiologists or when the model includes all of the physician characteristics, as shown in column (2).

The remaining characteristics have analogous effect sizes that are less than half as large as the number of cardiologists. Only one other measure has a meaningful relationship with mortality when estimated alone and with all of the other characteristics: physician experience with heart-failure patients. For a two standard deviation increase in the within-cell variation of this measure (5.2), the coefficient from column (1) implies that mortality falls by 0.26 percentage points (or $0.8 \%$ of the mean), and when the model includes all other physician characteristics measured here, the implied effect is a 0.21 percentage-point reduction (or $0.6 \%$ of the mean) 10

\footnotetext{
${ }^{10}$ When physician experience as an attending over the prior year is measured for all patients, a two-
} 
When controlling for other patient characteristics (Column 2), there are three other measures that have point estimates where these two-standard deviation increases in availability would lead to mortality changes of between 0.6 and $0.9 \%$ of the mean: the number of physicians graduating from a top 50 (out of 126) medical schools in terms of primary care and research, with the primary care ranking associated with lower mortality while the research ranking is associated with a modest increase in mortality; and the number of male physicians available is associated with an increase in mortality. Among these measures, the magnitudes are relatively small and only the number of physicians who gradated from a top 50 medical school in terms of primary care is statistically significant at the $10 \%$ level. For two standarddeviation increases in the other measures, mortality falls by less than 0.1 percentage points or lower.

All of these results should be interpreted in light of (1) they are within-hospital comparisons and (2) the measure of availability is measured with noise, which can dampen the estimated relationships. The largest (and most robust) result is that having more cardiologists present on the date of admission appears to reduce mortality for heart failure patients. The remainder of the paper further explores this result about the mix of specialists available on a given date in terms of treatment intensity, robustness checks, and other health conditions.

\subsection{Specialist Availability and Treatment Intensity}

\subsubsection{Direct treatment by a cardiologist}

Given that greater specialist availability appears to result in lower mortality, it is useful to understand how patients are treated differently across these dates. Figure 3 and Table 4 consider the most obvious implication: that the patients are more likely to be treated by cardiologists directly.

standard deviation increase in within-cell mean experience is associated with a 0.1 percentage-point increase in mortality, which is not statistically significant. 
The first result is the mean of the dependent variable: only $17 \%$ of these patients are assigned a cardiologist as an attending, and only $25 \%$ are substantively treated directly by a cardiologist. In fact, the claims data show that heart failure emergency patients are typically treated by internal medicine physicians.

Figure 3 is analogous to Figure 2; it shows that as the number of cardiologists available increases, so does the likelihood that the patient will be treated directly by a cardiologist. Increasing from zero to four-or-more cardiologists available is associated with a 26 percentagepoint increase in the likelihood of having cardiologist treatment.11

Meanwhile, Table 4 is similar to Table 3, but the outcome now is treatment by a cardiologist. Panel A shows that as the number of cardiologists observed increases from zero to one, the likelihood the patient receives a cardiologist as an attending physician increases by 11 percentage points. Increasing from zero to two-or-more observed cardiologists roughly doubles the estimate, an increase of 22 percentage points. These increases are remarkably stable to the addition of controls for patient characteristics, other physician characteristics, as well as the use of hospital $\mathrm{x}$ month $\mathrm{x}$ day-of-week fixed effects. Further, the number of non-cardiologist specialists available is unrelated to treatment by a cardiologist holding the number of cardiologists available constant.

Panel B considers the likelihood that a cardiologist is listed on the inpatient claim as an attending, operating, or other physician. The point estimates are similar to panel A: an increase of 10 and 18-20 percentage points when increasing to the two levels of cardiologist availability, respectively.

To place the mortality results in context, consider a simple model where the patient benefits from cardiologist availability only by being treated directly by a cardiologist, as opposed to consultations that are not recorded in the claims data. Under this strong assumption, to estimate marginal treatment effects of cardiologist care, the change in mortality as the level of available cardiologists increases in Table 3 can be divided by the corresponding change

\footnotetext{
${ }^{11}$ Figure A2 shows a similar relationship with assignment to a cardiologist as an attending physician, where increasing from zero to four-or-more cardiologists is associated with a 30 percentage-point increase.
} 
in cardiologist treatment from Table 4. Increasing from zero to one cardiologist appears to reduce mortality by 0.0065 , and dividing by 0.10 (the increase in any cardiologist treatment) implies that cardiologist treatment reduces mortality by 6.5 percentage points. Similarly, an analogous increase in availability from one to two-or-more cardiologists implies that cardiologist treatment results in a 6.3 percentage-point reduction in mortality. These estimates are qualitatively similar to the (more precise) OLS estimate in Table 4 (-8 percentage points), albeit smaller in magnitude as expected given the likely direction of selection bias.

It is reassuring that similar marginal treatment effects are found for the different levels of variation in availability in the sense that they help rule out some competing explanations. For example, if the gain from having a cardiologist treat a given heart failure patient resulted in a cardiologist being summoned to the hospital and re-introduce selection bias, this is a less likely scenario in the instance when more than one cardiologist is observed in the data because the other cardiologist(s) could have treated the patient.

\subsubsection{Procedures and hospital charges}

Table 5 reports results for other measures of treatment intensity. Panel A shows that operations on the cardiovascular system increase substantially with the observed number of cardiologists. $22 \%$ of these patients undergo such a major operation, and increasing the number of available cardiologists from zero to two or more on the date of admission increases the likelihood by 1.9 percentage points, or $9 \%$ of the mean. Similarly, cardiac catheterization is an invasive procedure that can lead to subsequent care and is often used to measure treatment intensity for cardiac patients and has a sample mean of 0.08 . This procedure is again significantly more likely with additional cardiologists observed. Here, the coefficient when going from zero to two or more is 0.012 . This is consistent with the literature documenting that specialist treatment is associated with more invasive treatments. For context, Table A5 shows that having a cardiologist attending is associated with a $50 \%$ increase in the likelihood of an operation on the cardiovascular system in a model with full controls, which is similar 
to the increase found in Table 5 re-scaled by the likelihood of being assigned a cardiologist as an attending.

The lower panels report results when the outcomes are measures of utilization in the form of the number of major procedures over the 30 days following admission and hospital charges during the index admission: list prices that are used in negotiations with payers and are positively correlated with treatment intensity. Similar to the catheterization result, cardiologist availability is positively related to the number of major procedures overall.

As for charges, increasing from zero to two or more cardiologists is associated $\$ 600$ higher list fees. If the increase in hospital charges is due to having direct treatment by a cardiologist, then the implied effect of the attending assignment would be on the order of $\$ 3000$ in charges during the index admission, or about $12 \%$ of the mean. ${ }^{12}$

\subsubsection{Medicare Spending}

Another policy-relevant measure of utilization is Medicare spending. A limitation with these inpatient claims is that they do not include physician fees paid to the specialists, which is of course highly relevant to any discussion of cost effectiveness. Table 6 reports results using a $20 \%$ random sample of beneficiaries where these physician fees are observed in addition to the inpatient and outpatient facility claims.

When a cardiologist is assigned to be the attending physician, index-event total spending is $\$ 2300$ higher. When we add treatment by a cardiologist including the operating and other physician IDs, this increases to $\$ 3500$. When the empirical strategy that focuses on cardiologist availability is used, the estimates are not precisely estimated, but they suggest no relationship when increasing from zero to one cardiologist available and $\$ 218$ higher spending when moving from zero to two-or-more cardiologists available (s.e. $=371$ ).

In terms of 1 -year spending, the average is $\$ 33,000$. Interestingly, patients assigned to cardiologists as their attending physician have only slightly higher 1-year spending (\$323, s.e.

\footnotetext{
${ }^{12}$ With typical cost to charge ratios on the order of 0.5 , this would imply a change in costs during the initial hospital stay on the order of $\$ 1500$.
} 
$=874$, while adding in the operating and other physicians results in an increase of $\$ 2700$.

When the number of available cardiologists increases from zero to two or more, the 1-year spending is found to be lower by $\$ 760$, but the estimate is again not precisely estimated $($ s.e. $=1361) \cdot 13$

Another commonly used measure of short-term patient health and utilization is 30-day readmission. Table A7 shows that cardiologist availability is relatively unrelated to this outcome, with coefficients and implied effects that are close to zero.

Overall, these estimates suggest that cardiologist treatment results in higher Medicare spending on the order of $\$ 3000$, primarily due to greater treatment at the initial hospitalization. Recall that under the strong assumption that cardiologist availability only affects patients by being treated by a cardiologist directly, the implied effect of cardiologist treatment on 1-year mortality is 6 percentage points. This in turn would imply a cost per at least one life year saved of $\$ 50,000(=3000 / 0.06)$. This is substantially below the $\$ 100,000$ $\$ 250,000$ value of a statistical life year often used in cost effectiveness analysis. While useful for context, this estimate may be biased upward or downward due to measurement error and the potential influences of cardiologist availability that go beyond those measured by Medicare spending.

\subsection{Heterogeneous Treatment Effects}

Given that cardiologists tend to be assigned to somewhat healthier patients, it is possible that the effects of cardiologists vary with the patients that are typically seen as more appropriate. It is likely that returns to specialty care are non-monotonic in patient health, as the healthiest patients do not require invasive procedures and patients in the worst health are not eligible

\footnotetext{
${ }^{13} 100 \%$ claims are available for facility fees, but the initial stay has facility payments that are relatively fixed by the diagnosis through Medicare's prospective payment system. Table A6 reports results for index-admission facility fees and 1-year payments made to inpatient and outpatient facilities. Cardiologist availability is associated with $\$ 300$ higher spending at the index admission when increasing from zero to two-or-more cardiologists; the estimate drops to a statistically-insignificant $\$ 100$ higher spending at one year, suggesting that post-discharge spending is modestly lower when there are more cardiologists available, offsetting higher spending found at the time of the initial hospitalization.
} 
for those procedures.

To investigate this further, a probit model predicting 1-year mortality was estimated using the full set of patient controls, and the sample was then divided into two based on the median of this measure. Table 7 shows that the point estimates are larger in magnitude for patients in worse health. The relationship between availability and cardiologist assignment is fairly similar across the two samples. Unfortunately, the standard errors more than double when the sample is divided in half, which makes it difficult to make comparisons with any precision.

In addition to heterogeneity across patients, there could be heterogeneity across hospitals. For example, are lower-quality hospitals especially prone to need specialists to achieve better outcomes or do the mortality differences between specialist and non-specialist physicians scale with hospital quality? As a first look along this line, the sample was divided into two groups based on overall patient volume, with the idea that higher-quality hospitals have higher volumes Birkmeyer et al., 2002. Table 7 again shows larger standard errors, but this time the point estimates are relatively similar across both high- and low-volume hospitals. High-volume hospitals are more likely to assign a cardiologist attending compared to lowvolume hospitals (22\% vs. $13 \%$ ) and the effect of availability is larger at the low-volume hospitals. The implied effect of a cardiologist attending (if this is the only channel by which cardiologist availability impacts mortality) is a 5 percentage-point reduction in mortality in low-volume hospitals and an 8 percentage-point reduction in high-volume hospitals. This is suggestive evidence that returns to specialty care are somewhat larger in higher-quality hospitals.

As noted above, one concern is that by the nature of the proxy measurement for cardiologist availability, more patients admitted the same day can lead to more cardiologists observed, and this greater volume can have its own direct effects on care via congestion. Further, holidays are typically less busy but may have differences in scheduling so that availability could be correlated with patient characteristics. Last, the proxy may be more accurate when more 
patients are observed because they are more likely to trace out the availability of physician types ${ }^{14}$ The main results were shown to be robust to the inclusion of flexible controls for how busy the hospital is on any given date. To investigate these issues further, Panel $\mathrm{C}$ reports results when the data are divided into dates when the number of patients entering a given hospital is above or below the mean for that hospital. The standard errors again double when the sample is divided in this way, but the point estimates continue to point to sizeable reductions in mortality when there are more cardiologists available regardless of the volume level.

\subsection{Specialist Availability and Other Health Conditions}

A similar analysis can be conducted for other common admissions that occur via the emergency room and have a substantial 1-year mortality rate. To consider the role of specialists, the most common type of specialty among attending physicians assigned to patients was identified: cardiologists are most common for acute myocardial infarction (heart attack) and cardiac dysrhythmia, neurologists for stroke patients, orthopedic specialists for a wide range of fractures including the commonly studied emergency condition of hip fracture, and pulmonologists for pneumonia patients.

Table 8 shows that across these conditions, greater specialist availability tends to be associated with substantially lower mortality. In models with full controls, going from zero to two-or-more specialists is associated with a 2.7 percentage-point reduction in mortality among AMI patients, a 2.0 percentage-point reduction for cardiac dysrhythmia patients, a 2.5 percentage-point reduction for stroke patients, 2.6 percentage-point reduction for inpatients with any type of fracture, and a 3.1 percentage-point reduction for patients with hip fracture in particular. An exception is pneumonia, where a greater availability of pulmonologists is associated with a small increase in mortality (0.5 percentage points), which is not statistically

\footnotetext{
${ }^{14}$ As another check on proxy quality, similar results are also found when the maximum number of physicians is calculated for each hospital over the sample period and the model is estimated for different levels of the number of physicians observed on a given date relative to this maximum.
} 
significant.

The table also shows that (1) many patients are not treated by the most-common type of specialist, and (2) greater availability of specialists substantially increases the likelihood of treatment by one. For the cardiac conditions and fractures, specialists provide direct treatment in about half of the cases, and nearly $80 \%$ of the hip fracture cases. In terms of attending physician assignment, between $32-41 \%$ of these patients were assigned a specialist as the attending physician. Specialist involvement is lower for stroke and pneumonia patients, which suggests that the claims data should be regarded as identifying substantial involvement of a specialist rather than any consultation whatsoever.

The mortality results are more sensitive to the inclusion of patient controls compared to the main analysis of heart failure patients. While the estimates are not statisticallysignificantly different with or without full controls, the reduction in the magnitude of the coefficient with controls suggests more caution when evaluating the results 15 These reductions also suggest some caution for the main heart failure results, although the ubiquity of that health condition and the relative insensitivity to the inclusion of controls are more supportive of the exogeneity assumption.

Overall, patients admitted with common emergency conditions appear to benefit from the availability of specialists, although this is not found in the case of pulmonologists, where either the measurement issues are more severe or the returns are lower.

One remaining question is whether the greater availability of specialists affects the treatment intensity and outcomes for patients with conditions that they do not usually treat. The main results showed that for heart failure patients, the availability of non-cardiologists did not affect their care or outcomes. Table 8 continues to find that the availability of specialists other than one most common for a given condition does not affect the likelihood of treatment by the most-common specialist, which is not surprising as the empirical model

\footnotetext{
${ }^{15}$ For example, it is possible that for less-common conditions hospitals are more likely to either schedule or call in a specialist to treat these patients. One solution would be to look at specialists who admitted a patient prior to the time of admission rather than the date of admission, but these claims data do not include the time of admission.
} 
holds the number of most-common specialists constant. In terms of mortality, the effects of the availability of "other specialists" tend to be small (mirroring the results for number

of other specialists in Table 2), and the sign is not consistent across the conditions. These results imply that within the range of variation observed here, an increase in the proportion of physicians who are specialists improves outcomes for patients who are commonly treated by those specialties; such an increase does not appear to affect the treatment or health outcomes for those with other common emergency conditions.

\section{Conclusion}

There are concerns that moral hazard problems in the US healthcare system have led to an over-reliance on specialists, which are associated with greater resource use and only mixed evidence of improved quality of care. As a result there are often calls for greater incentives to channel care through less-intensive general practitioners.

Comparisons of treatment and outcomes for patients treated by specialists versus nonspecialists may be confounded by selection bias. This paper uses 100\% Medicare claims data to calculate proxies for physician characteristics of those available on the date of admission. For heart failure patients, arriving on a date with more cardiologists results in lower mortality. The presence of more cardiologists also results in a greater likelihood that the patient will be treated directly by a cardiologist, a higher likelihood of a major operation, and higher Medicare spending. For context, the results are suggestive that this additional treatment is worth the extra expense: under strong assumptions, the return to specialty care appears high, with a cost per at least one life-year saved on the order of $\$ 50,000$.

In addition, the volume of heart failure patients seen by the physician over the past year is also associated with lower mortality. While this effect is statistically significant, the economic magnitude is half as large as the effects of specialty care. Other physician characteristics, including physician sex, medical-school quality, and years of experience are largely unrelated 
to patient health.

There are a number of limitations when interpreting the estimates. First, the measures of availability are only proxies, and so a lack of a relationship found for some measures may reflect the quality of the proxy rather than a lack of a true effect. Second, the comparisons are made within hospitals to absorb differences in practice environments, but the results may not apply to comparisons of physicians across hospitals. Third, while the availability of specialists may benefit emergency patients, they may add to costs when they are available to treat non-emergency patients. The current results show that at least among emergency patients with common conditions, the availability of "other specialists" does not affect treatment intensity or outcomes. This suggests that within the range of variation considered here, the benefits of specialist availability are not countered by wasteful care for other emergency patients. A more-general limitation of the current analysis is that these estimates are for emergency patients (both main effects and spillovers on other patients), and effects of specialist treatment for those with scheduled visits may well be different.

The results here suggest that greater specialist availability improves survival at a relatively low cost. If calls for greater reliance on lower-cost general practitioners are heeded, such a shift in treatment priorities would likely come at the cost of lower-quality care for emergency patients. 


\section{References}

Jason Abaluck, Leila Agha, Chris Kabrhel, Ali Raja, and Arjun Venkatesh. The determinants of productivity in medical testing: Intensity and allocation of care. American Economic Review, 106(12):3730-3764, 2016. doi: 10.1257/aer.20140260.

Leila Agha, Brigham Frandsen, and James B. Rebitzer. Fragmented division of labor and healthcare costs: Evidence from moves across regions. Journal of Public Economics, 169: 144-159, 2019. doi: 10.1016/j.jpubeco.2018.11.001.

David Archampong, David Borowski, Peer Wille-Jørgensen, and Lene H Iversen. Workload and surgeons specialty for outcome after colorectal cancer surgery. Cochrane Database of Systematic Reviews, 2012. doi: 10.1002/14651858.cd005391.pub3.

John Z. Ayanian, Paul J. Hauptman, Edward Guadagnoli, Elliott M Antman, Chris L. Pashos, and Barbara J. Mcneil. Knowledge and practices of generalist and specialist physicians regarding drug therapy for acute myocardial infarction. New England Journal of Medicine, 331(17):1136-1142, 1994. doi: 10.1056/nejm199410273311707.

Katherine Baicker and Amitabh Chandra. Medicare spending, the physician workforce, and beneficiaries' quality of care. Health Affairs, 23(Suppl1), 2004a. doi: 10.1377/hlthaff.w4. 184.

Katherine Baicker and Amitabh Chandra. The productivity of physician specialization: Evidence from the medicare program. American Economic Review, 94(2):357-361, 2004b. doi: 10.1257/0002828041301461.

Sanjay Basu, Seth A. Berkowitz, Robert L. Phillips, Asaf Bitton, Bruce E. Landon, and Russell S. Phillips. Association of primary care physician supply with population mortality in the united states, 2005-2015. JAMA Internal Medicine, 179(4):506, 2019. doi: 10.1001/ jamainternmed.2018.7624.

G. S. Becker and K. M. Murphy. The division of labor, coordination costs, and knowledge. The Quarterly Journal of Economics, 107(4):1137-1160, 1992. doi: 10.2307/2118383.

Ernst R. Berndt, Robert S. Gibbons, Anton Kolotilin, and Anna Levine Taub. The heterogeneity of concentrated prescribing behavior: Theory and evidence from antipsychotics. Journal of Health Economics, 40:26-39, 2015. doi: 10.1016/j.jhealeco.2014.11.003.

H. K. Berthold, I. Gouni-Berthold, K. P. Bestehorn, M. Böhm, and W. Krone. Physician gender is associated with the quality of type 2 diabetes care. Journal of Internal Medicine, 264(4):340-350, 2008. doi: 10.1111/j.1365-2796.2008.01967.x.

John D. Birkmeyer, Andrea E. Siewers, Emily V.a. Finlayson, Therese A. Stukel, F. Lee Lucas, Ida Batista, H. Gilbert Welch, and David E. Wennberg. Hospital volume and surgical mortality in the united states. New England Journal of Medicine, 346(15):1128-1137, 2002. doi: 10.1056/nejmsa012337.

John D. Birkmeyer, Therese A. Stukel, Andrea E. Siewers, Philip P. Goodney, David E. Wennberg, and F. Lee Lucas. Surgeon volume and operative mortality in the united states. New England Journal of Medicine, 349(22):2117-2127, 2003. doi: 10.1056/nejmsa035205.

Paul N Casale, Jayne L Jones, Flossie E Wolf, Yanfen Pei, and L.marlin Eby. Patients treated by cardiologists have a lower in-hospital mortality for acute myocardial infarction. Journal of the American College of Cardiology, 32(4):885-889, 1998. doi: 10.1016/s0735-1097(98) 00325-8.

Clément De Chaisemartin. Tolerating defiance? local average treatment effects without 
monotonicity. Quantitative Economics, 8(2):367-396, 2017. doi: 10.3982/qe601.

David Chan, Matthew Gentzkow, and Chuan Yu. Selection with variation in diagnostic skill: Evidence from radiologists. 2020. doi: 10.3386/w26467.

David C. Chan. Influence and information in team decisions: Evidence from medical residency. American Economic Journal: Economic Policy, Forthcoming, forthcoming.

Amitabh Chandra and Douglas O. Staiger. Productivity spillovers in health care: Evidence from the treatment of heart attacks. Journal of Political Economy, 115(1):103-140, 2007. doi: $10.1086 / 512249$.

Michael E. Chernew, Lindsay Sabik, Amitabh Chandra, and Joseph P. Newhouse. Would having more primary care doctors cut health spending growth? Health Affairs, 28(5): 1327-1335, 2009. doi: 10.1377/hlthaff.28.5.1327.

Janet Currie and W. Bentley Macleod. Diagnosing expertise: Human capital, decision making, and performance among physicians. Journal of Labor Economics, 35(1):1-43, 2017. doi: $10.1086 / 687848$.

David Cutler, Jonathan S. Skinner, Ariel Dora Stern, and David Wennberg. Physician beliefs and patient preferences: A new look at regional variation in health care spending. American Economic Journal: Economic Policy, 11(1):192-221, 2019. doi: 10.1257/pol. 20150421.

Joseph J. Doyle, Steven M. Ewer, and Todd H. Wagner. Returns to physician human capital: Evidence from patients randomized to physician teams. Journal of Health Economics, 29 (6):866-882, 2010. doi: 10.1016/j.jhealeco.2010.08.004.

Andrew J. Epstein and Sean Nicholson. The formation and evolution of physician treatment styles: An application to cesarean sections. Journal of Health Economics, 28(6):1126-1140, 2009. doi: 10.1016/j.jhealeco.2009.08.003.

Elliott S. Fisher, David E. Wennberg, Therese A. Stukel, Daniel J. Gottlieb, F. L. Lucas, and Étoile L. Pinder. The implications of regional variations in medicare spending. part 2: Health outcomes and satisfaction with care. Annals of Internal Medicine, 138(4):288, 2003. doi: 10.7326/0003-4819-138-4-200302180-00007.

Leslie Allison Gillum and S. Claiborne Johnston. Influence of physician specialty on outcomes after acute ischemic stroke. Journal of Hospital Medicine, 3(3):184-192, 2008. doi: 10. 1002/jhm.313.

J. Alison Glover. The incidence of tonsillectomy in school children. Proceedings of the Royal Society of Medicine, 31(10):1219-1236, 1938. doi: 10.1177/003591573803101027.

Alan S Go, Rajni K Rao, Kent W Dauterman, and Barry M Massie. A systematic review of the effects of physician specialty on the treatment of coronary disease and heart failure in the united states. The American Journal of Medicine, 108(3):216-226, 2000. doi: 10.1016/s0002-9343(99)00430-1.

L.b. Goldstein, D.b. Matchar, J. Hoff-Lindquist, G.p. Samsa, and R.d. Horner. Va stroke study: Neurologist care is associated with increased testing but improved outcomes. Neurology, 61(6):792-796, 2003. doi: 10.1212/01.wnl.0000082724.77447.3a.

Brad N. Greenwood, Seth Carnahan, and Laura Huang. Patient-physician gender concordance and increased mortality among female heart attack patients. Proceedings of the National Academy of Sciences, 115(34):8569-8574, 2018. doi: 10.1073/pnas.1800097115.

M. J. Hall, C. J. DeFrances, S. N. Williams, A. Golosinskiy, and A. Schwartzman. volume 29 of National Health Statistics Reports. 
Leslie R. Harrold, Terry S. Field, and Jerry H. Gurwitz. Knowledge, patterns of care, and outcomes of care for generalists and specialists. Journal of General Internal Medicine, 14 (8):499-511, 1999. doi: 10.1046/j.1525-1497.1999.08168.x.

A. Hartz and P. A. James. A systematic review of studies comparing myocardial infarction mortality for generalists and specialists: Lessons for research and health policy. The Journal of the American Board of Family Medicine, 19(3):291-302, 2006. doi: 10.3122/ jabfm.19.3.291.

James Heckman and Edward Vytlacil. Structural equations, treatment effects and econometric policy evaluation. Econometrica, 73:669-738, 2005. doi: 10.1111/j.1468-0262.2005. 00594.x.

Guido W. Imbens and Joshua D. Angrist. Identification and estimation of local average treatment effects. Econometrica, 62(2):467-475, 1994. doi: 10.2307/2951620.

James G. Jollis, Elizabeth R. Delong, Eric D. Peterson, Lawrence H. Muhlbaier, Donald F. Fortin, Robert M. Califf, and Daniel B. Mark. Outcome of acute myocardial infarction according to the specialty of the admitting physician. New England Journal of Medicine, 335(25):1880-1887, 1996. doi: 10.1056/nejm199612193352505.

Dennis T. Ko, Peter C. Austin, Benjamin T. B. Chan, and Jack V. Tu. Quality of care of international and canadian medical graduates in acute myocardial infarction. Archives of Internal Medicine, 165(4):458, 2005. doi: 10.1001/archinte.165.4.458.

Toru Kondo, Takahiro Okumura, Yuya Matsue, Atsushi Shiraishi, Nobuyuki Kagiyama, Tetsuo Yamaguchi, Shunsuke Kuroda, Keisuke Kida, Atsushi Mizuno, and Shogo Oishi. Specialty-related differences in the acute-phase treatment and prognosis in patients with acute heart failure - insights from reality-ahf —. Circulation Journal, 83(1):174-181, 2018. doi: 10.1253/circj.cj-18-0724.

David M. Levine, Bruce E. Landon, and Jeffrey A. Linder. Quality and experience of outpatient care in the united states for adults with or without primary care. JAMA Internal Medicine, 179(3):363-372, 2019. doi: 10.1001/jamainternmed.2018.6716.

Herng-Ching Lin, Sudha Xirasagar, Chi-Hung Chen, and Yi-Ting Hwang. Physician's case volume of intensive care unit pneumonia admissions and in-hospital mortality. American Journal of Respiratory and Critical Care Medicine, 177(9):989-994, 2008. doi: 10.1164/ rccm.200706-813oc.

David Meltzer. Hospitalists and the doctor-patient relationship. The Journal of Legal Studies, 30(S2):589-606, 2001. doi: 10.1086/339294.

Janet B. Mitchell, David J. Ballard, Jack P. Whisnant, Carol J. Ammering, Gregory P. Samsa, and David B. Matchar. What role do neurologists play in determining the costs and outcomes of stroke patients? Stroke, 27(11):1937-1943, 1996. doi: 10.1161/01.str.27. 11.1937.

Debra L. Roter, Judith A. Hall, and Yutaka Aoki. Physician gender effects in medical communication. Jama, 288(6):756, 2002. doi: 10.1001/jama.288.6.756.

David M Shahian and Sharon-Lise T Normand. The volume-outcome relationship: from luft to leapfrog. The Annals of Thoracic Surgery, 75(3):1048-1058, 2003. doi: 10.1016/ s0003-4975(02)04308-4.

David Silver. Haste or waste? peer pressure and productivity in the emergency department. SSRN Working Paper, 2020. URL http://dx.doi.org/10.2139/ssrn.3588769.

Jonathan S. Skinner, Douglas O. Staiger, and Elliott S. Fisher. Is technological change in 
medicine always worth it? the case of acute myocardial infarction. Health Affairs, 25 (Suppl1), 2006. doi: 10.1377/hlthaff.25.w34.

Bruce Steinwald, Paul Ginsburg, Caitlin Brandt, Sobin Lee, and Kavita Patel. We need more primary care physicians: Here's why and how, Jul 2019. URL https://www.brookings.edu/blog/usc-brookings-schaeffer-on-health-policy/ 2019/07/08/we-need-more-primary-care-physicians-heres-why-and-how/.

Yusuke Tsugawa, Anupam B. Jena, Jose F. Figueroa, E. John Orav, Daniel M. Blumenthal, and Ashish K. Jha. Comparison of hospital mortality and readmission rates for medicare patients treated by male vs female physicians. JAMA Internal Medicine, 177(2):206, 2017a. doi: 10.1001/jamainternmed.2016.7875.

Yusuke Tsugawa, Anupam B Jena, E John Orav, and Ashish K Jha. Quality of care delivered by general internists in us hospitals who graduated from foreign versus us medical schools: observational study. Bmj, 2017b. doi: 10.1136/bmj.j273.

Yusuke Tsugawa, Ashish K. Jha, Joseph P. Newhouse, Alan M. Zaslavsky, and Anupam B. Jena. Variation in physician spending and association with patient outcomes. JAMA Internal Medicine, 177(5):675, 2017c. doi: 10.1001/jamainternmed.2017.0059.

Shanmugam Uthamalingam, Jagdesh Kandala, Vijairam Selvaraj, William Martin, Marlyn Daley, Eshan Patvardhan, Robert Capodilupo, Stephanie Moore, and James L. Januzzi. Outcomes of patients with acute decompensated heart failure managed by cardiologists versus noncardiologists. The American Journal of Cardiology, 115(4):466-471, 2015. doi: 10.1016/j.amjcard.2014.11.034.

Christopher Jd Wallis, Bheeshma Ravi, Natalie Coburn, Robert K Nam, Allan S Detsky, and Raj Satkunasivam. Comparison of postoperative outcomes among patients treated by male and female surgeons: a population based matched cohort study. $B m j$, 2017. doi: $10.1136 / \mathrm{bmj} . j 4366$.

J. Wennberg and A. Gittelsohn. Small area variations in health care delivery: A populationbased health information system can guide planning and regulatory decision-making. Science, 182(4117):1102-1108, 1973. doi: 10.1126/science.182.4117.1102.

Salman Zaheer, Samuel D. Pimentel, Kristina D. Simmons, Lindsay E. Kuo, Jashodeep Datta, Noel Williams, Douglas L. Fraker, and Rachel R. Kelz. Comparing international and united states undergraduate medical education and surgical outcomes using a refined balance matching methodology. Annals of Surgery, 265(5):916-922, 2017. doi: 10.1097/ sla.0000000000001878.

M. Justin Zaman, Robert Fleetcroft, Max Bachmann, Toomas Sarev, Susan Stirling, Allan Clark, and Phyo Kyaw Myint. Association of increasing age with receipt of specialist care and long-term mortality in patients with non-st elevation myocardial infarction. Age and Ageing, 45(1):96-103, 2015. doi: 10.1093/ageing/afv162. 
Figure 1: Within-cell Variation:

Vigntiles in Number of Cardiologists Observed

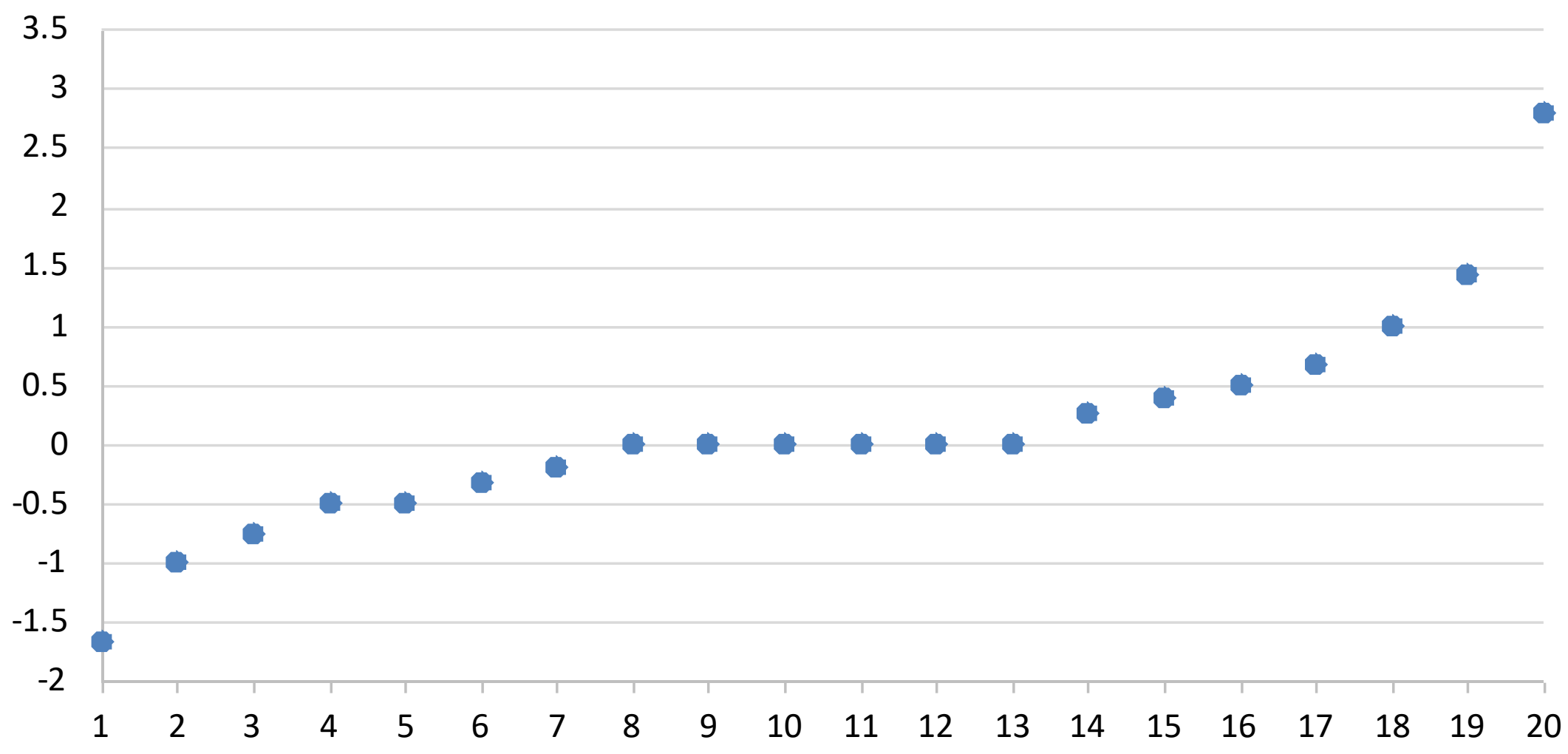

This figure rep orts 20 equally-spaced points in the distribution of the standard deviation of the number of cardiologists observed on the same date as the patient's admission after this availability measure has been de-meaned at the hospital $\mathrm{x}$ quarter $\mathrm{x}$ day-ofweek level. 


\section{Figure 2: Predicted Mortality \& Actual Mortality}

vs. Cardiologist Availability

\section{Mortality \& \\ Predicted \\ Mortality}

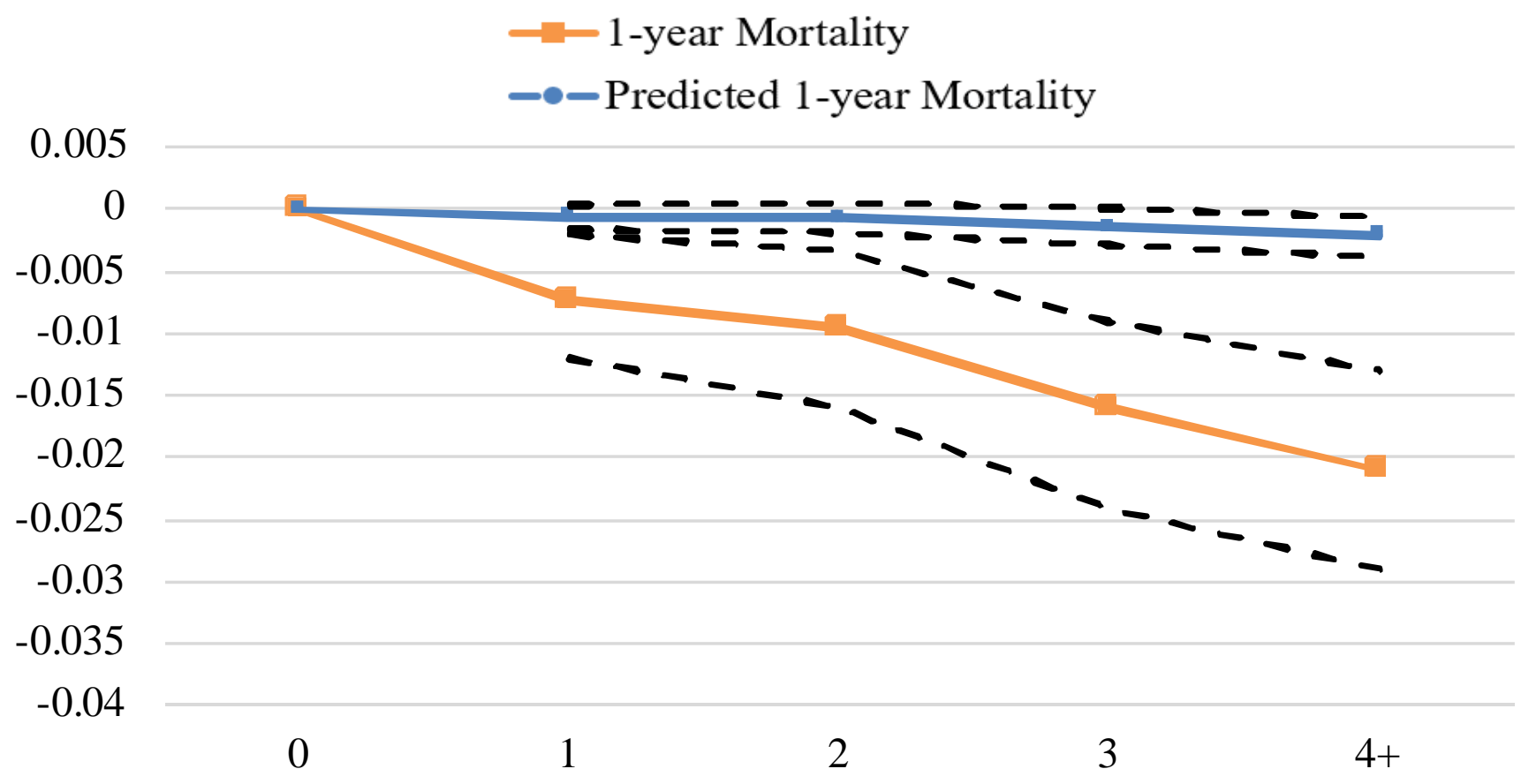

Available Cardiologists

This figure plots coefficient estimates of the relationship between predicted and actual 1-year mortality versus the number of available cardiologists from a model that includes hospital x quarter $\mathrm{x}$ day-of-week fixed effects. Predicted one-year mortality is calculated using a probit model and the full set of patient characteristics described in the text. Dotted lines represent 95\% confidence intervals calculated using standard errors that were clustered at the hospital level. 


\section{Figure 3: Cardiologist Treatment vs. Cardiologist Availability}

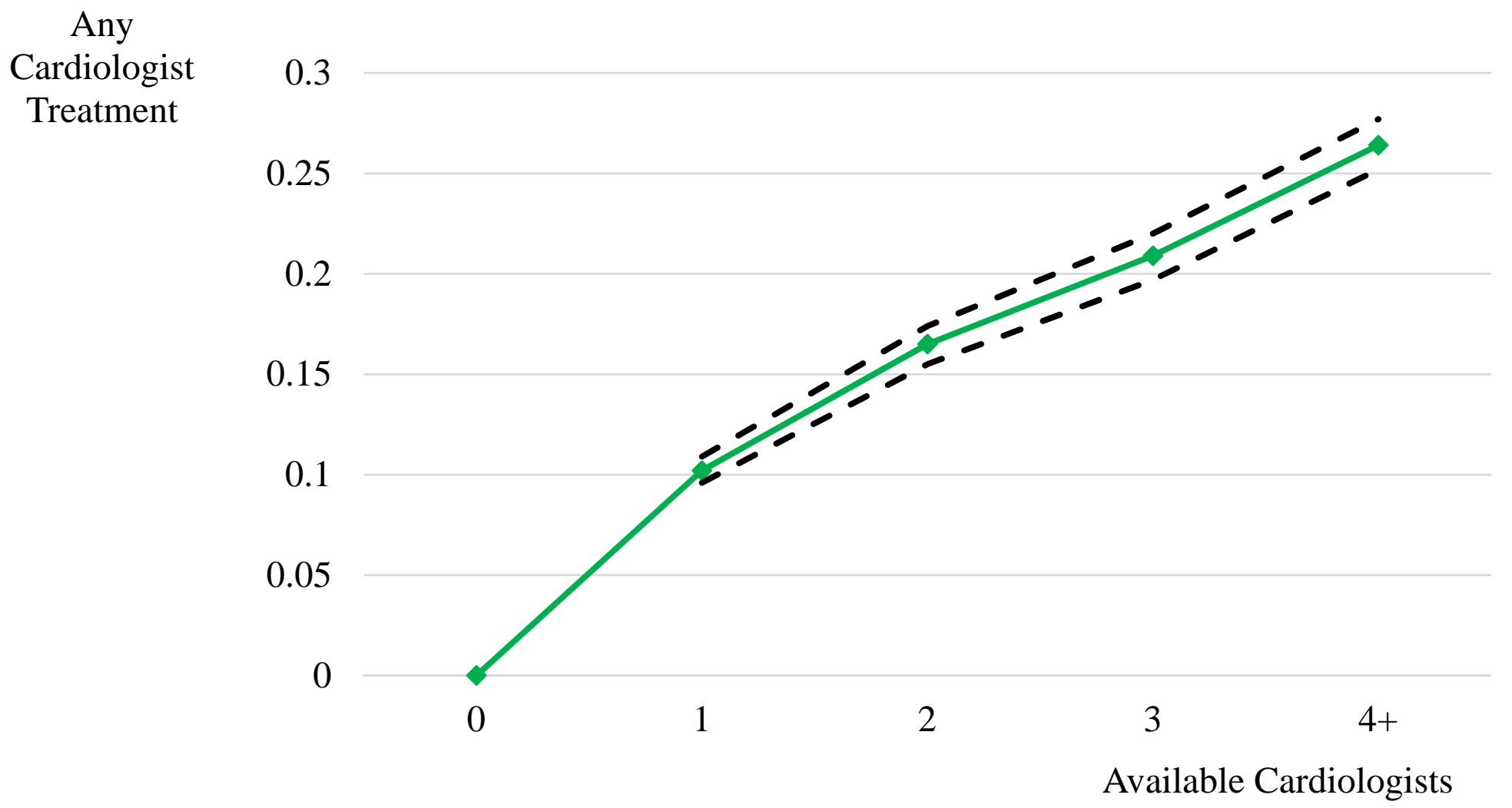

This figure plots coefficient estimates of the relationship between cardiologist treatment versus the number of available cardiologists from a model that includes hospital x quarter x day-of-week fixed effects. Dotted lines represent 95\% confidence intervals calculated using standard errors that were clustered at the hospital level. 


$=$

Attending physician assigned:

A. Patient characteristics

$\frac{\text { Non-Cardiol }}{(1)}$

Age

Male

White

African American

Hispanic

1-year lagged spending
Cardiologist

$$
78.4
$$

0.44

0.84

0.12

0.02

13334
Date when number of cardiologists observed is:

\begin{tabular}{cc} 
Low & High \\
\hline$(3)$ & $(4)$ \\
78.3 & 78.2 \\
0.45 & 0.46 \\
0.85 & 0.86 \\
0.11 & 0.10 \\
0.02 & 0.02 \\
13045 & 12913
\end{tabular}

\section{B. Hospital environment per day}

\begin{tabular}{lllll} 
Number of physicians & 14.8 & 15.0 & 13.6 & 15.7 \\
Number of cardiologists & 1.59 & 2.15 & 1.21 & 3.11 \\
Number of patients & 21.3 & 21.5 & 19.6 & 22.0 \\
\cline { 2 - 4 }
\end{tabular}

Observations 909,083

Columns (1) and (3) are sample means; Columns (2) and (4) are calculated by adding these means and the point estimates from models of each characteristic regressed on an indicator that the patient was assigned to a cardiologist attending (Column 2) or arrived on a date when the number of cardiologists observed is higher than the cell mean (Column 4), along with hospital x quarter x day-of-week fixed effects. 
Dependent Variable: 1-year mortality

$\begin{array}{ccc} & (1) & (2) \\ \text { Cardiologist Attending } & -0.086 & -0.078 \\ (0.0024) & (0.0023)\end{array}$

(6)

(7)

(8)

(9)

(10)

Any Cardiologist Treatment
$-0.10$
$-0.082$
$(0.0020)$
(0.0019)

Number of Cardiologists Observed $=1$

$\begin{array}{cccccc}-0.0070 & -0.0072 & -0.0066 & -0.0064 & -0.0054 & -0.0052 \\ (0.0025) & (0.0026) & (0.0025) & (0.0025) & (0.0052) & (0.0053) \\ & & & & & \\ -0.0128 & -0.0133 & -0.0122 & -0.0119 & -0.0126 & -0.0121 \\ (0.0030) & (0.0031) & (0.0031) & (0.0031) & (0.0064) & (0.0064) \\ & & & & & \\ -0.00005 & -0.0001 & 0.0001 & 0.0000005 & 0.00004 & -0.00009 \\ (0.0004) & (0.0005) & (0.0005) & (0.0005) & (0.0009) & (0.0010)\end{array}$

\section{Controls for:}

Number of physicians and patients

Patient characteristics

Other physician characteristics

$\begin{array}{cc}\text { No } & \text { Yes } \\ \text { No } & \text { Yes } \\ \text { No } & \text { No } \\ \text { Hospital- } & \text { Hospital- } \\ \text { Quarter- } & \text { Quarter- } \\ \text { Day } & \text { Day }\end{array}$

No
No
No
Hospital-
Quarter-
Day

Yes
Yes
No
Hospital-

$\begin{array}{cc}\text { No } & \text { Yes } \\ \text { No } & \text { No } \\ \text { No } & \text { No } \\ \text { Hospital- } & \text { Hospital- }\end{array}$

Fixed effects

0.326

Mean of the dependent variable 909,083

Models that control for the number of physicians and patients include indicators for each value observed in the same hospital-date cell. Controls for patient characteristics include those listed in Table 1, including indicators for each age and quintiles of lagged Medicare spending. Other physician characteristics are described in Table 3. Robust standard errors in parentheses, clustered by hospital. 
Dependent Variable: 1-year mortality

Physician types observed on the date of admission:

(1)

\begin{tabular}{cc}
-0.0035 & -0.0036 \\
$(0.0007)^{* * *}$ & $(0.0007)^{* * *}$ \\
\hline 0.0004 & -0.0004 \\
$(0.0005)$ & $(0.0005)$ \\
\hline-0.0007 & -0.0011 \\
$(0.0005)$ & $(0.0006)^{*}$ \\
\hline 0.00005 & 0.0008 \\
$(0.0005)$ & $(0.0006)$ \\
\hline-0.0002 & -0.0002 \\
$(0.0005)$ & $(0.0006)$ \\
\hline 0.0002 & 0.0006 \\
$(0.0006)$ & $(0.0006)$ \\
\hline-0.0008 & -0.0005 \\
$(0.003)$ & $(0.0028)$ \\
\hline-0.0005 & -0.0004 \\
$(0.0002)^{* *}$ & $(0.0002)^{* *}$ \\
\hline
\end{tabular}

Separate regressions

Yes

No

Mean of the dependent variable

Observations

0.326

909,083

Models include hospital x quarter $\mathrm{x}$ day-of-week fixed effects, as well as the full set of controls listed in Table

2. Robust standard errors in parentheses, clustered by hospital. ***= significant at 0.001 ; $*$ significant at 0.10 . 


\section{Table 4: Cardiologist Availability \& Cardiologist Assignment}

\section{A. Cardiologist Attending}

Number of Cardiologists Observed $=1$

Number of Cardiologists Observed $\geq 2$

Number of Other Specialists Observed

Controls for:

Patient characteristics

Other physician characteristics

Fixed effects

Mean of the dependent variable

Observations

\section{B. Any Cardiologist Treatment}

Number of Cardiologists Observed $=1$

Number of Cardiologists Observed $\geq 2$

Number of Other Specialists Observed

Controls for:

Patient characteristics

Other physician characteristics

Fixed effects

Mean of the dependent variable

Observations

All models include indicators for the number of physicians and the number of patients observed in the same hospital x quarter x day-of-week cell. Controls for patient characteristics and other physician characteristics are the same as those described in Table 2. Robust standard errors in parentheses, clustered by

hospital.

Dependent variable: Cardiologist attending

$\begin{array}{ccccc}(1) & (2) & (3) & (4) & (5) \\ 0.112 & 0.112 & 0.110 & 0.105 & 0.104 \\ (0.0033) & (0.0033) & (0.0032) & (0.0052) & (0.0051) \\ 0.218 & & & & \\ (0.0052) & 0.217 & 0.212 & 0.205 & 0.201 \\ & (0.0051) & (0.0050) & (0.0080) & (0.0078) \\ -0.0002 & & & & -0.0004 \\ (0.0004) & -0.0003 & 0.0005 & -0.0011 & (0.0008)\end{array}$

$\begin{array}{ccccc}\text { No } & \text { Yes } & \text { Yes } & \text { Yes } & \text { Yes } \\ \text { No } & \text { No } & \text { Yes } & \text { No } & \text { Yes } \\ \text { Hosp-Quarter-Day } & \text { Hosp-Quarter-Day } & \text { Hosp-Quarter-Day } & \text { Hosp-Month-Day } & \text { Hosp-Month-Day } \\ & & & & \\ 0.174 & & & & \\ 909,083 & & & \end{array}$

Dependent variable: Cardiologist attending, operating, or other

$\begin{array}{ccccc}(1) & (2) & (3) & (4) & (5) \\ 0.104 & 0.103 & 0.101 & 0.0967 & 0.0953 \\ (0.0035) & (0.0034) & (0.0034) & (0.0059) & (0.0058)\end{array}$

$\begin{array}{ccccc}0.196 & 0.194 & 0.190 & 0.183 & 0.179 \\ (0.0052) & (0.0051) & (0.0054) & (0.0084) & (0.0082) \\ -0.0001 & -0.0002 & 0.00054 & -0.0012 & -0.00050 \\ (0.0005) & (0.0005) & (0.0005) & (0.0009) & (0.0009)\end{array}$

$\begin{array}{ccccc}\text { No } & \text { Yes } & \text { Yes } & \text { Yes } & \text { Yes } \\ \text { No } & \text { No } & \text { Yes } & \text { No } & \text { Yes } \\ \text { Hosp-Quarter-Day } & \text { Hosp-Quarter-Day } & \text { Hosp-Quarter-Day } & \text { Hosp-Month-Day } & \text { Hosp-Month-Day }\end{array}$

0.259

909,083 
Table 5: Cardiologist Availability \& Short-term Treatment Intensity

Dependent Variable: Operation on the cardiovascular system

$\begin{array}{lccc} & (1) & (2) & (3) \\ \text { Number of Cardiologists Observed }=1 & 0.0084 & 0.0078 & 0.0076 \\ \text { Number of Cardiologists Observed } \geq 2 & (0.0021) & (0.0021) & (0.0021) \\ & & & 0.0175 \\ \text { Number of Other Specialists Observed } & 0.0192 & 0.0178 & (0.0026) \\ & (0.0027) & (0.0026) & 0.0013 \\ \end{array}$

Patient characteristics

Other physician characteristics

No

No

Yes

No

0.217
Controls for:
Cardiac catheterization (30-days)

$\begin{array}{ccc}(4) & (5) & (6) \\ 0.0062 & 0.0057 & 0.0057 \\ (0.0014) & (0.0013) & (0.0013) \\ & & \\ 0.0124 & 0.0112 & 0.0111 \\ (0.0018) & (0.0018) & (0.0018) \\ & & \\ 0.0005 & 0.0004 & 0.0005 \\ (0.0003) & (0.0003) & (0.0003)\end{array}$

Yes

Yes

$\begin{array}{lll}\text { No } & \text { Yes } & \text { Yes } \\ \text { No } & \text { No } & \text { Yes }\end{array}$

0.082
Dependent Variable: Number of procedures (30-days)

Number of Cardiologists Observed = 1 (7) 0.0213 (0.0079)

\section{(8)}

0.0187

(0.0078)

\subsection{5}

(0.0102)

0.0424

0.0061

(0.0100)

(0.0016)

0.0054

(0.0016)

Yes

No

No

0.997

909,083

Controls for:

Other physician characteristics

Mean of the dependent variable

Observations

Yes Yes

Yes

Hospital charges

(9)

0.0186

(0.0078)

0.0417

(0.0100)

0.0057

(0.0017)

Yes

$\longrightarrow$

\begin{tabular}{ccc}
\multicolumn{3}{c}{ Hospital charges } \\
$(10)$ & $(11)$ & $(12)$ \\
287 & 235 & 220 \\
$(158)$ & $(158)$ & $(158)$ \\
& & \\
774 & 644 & 612 \\
$(217)$ & $(215)$ & $(215)$ \\
104 & 94 & 98 \\
$(38.1)$ & $(37.9)$ & $(38.8)$ \\
No & & \\
No & Yes & Yes \\
& No & Yes \\
24829 & & \\
& &
\end{tabular}

All models include indicators for the number of physicians and the number of patients observed in the same hospital x quarter x day-of-week cell. Controls for patient characteristics and other physician characteristics are the same as those described in Table 2. Robust standard errors in parentheses, clustered by hospital. 
Table 6: Cardiologists \& Medicare Spending

\begin{tabular}{|c|c|c|c|c|c|c|}
\hline \multirow[t]{2}{*}{ Dependent Variable: } & \multicolumn{3}{|c|}{$\begin{array}{c}\text { Index Admission Facility } \\
+ \text { Physician Fees }\end{array}$} & \multicolumn{3}{|c|}{$\begin{array}{c}\text { 1-year Facility } \\
+ \text { Physician Fees } \\
\end{array}$} \\
\hline & (1) & $(2)$ & (3) & (4) & (5) & (6) \\
\hline \multirow[t]{2}{*}{ Cardiologist Attending } & 2337 & & & 323 & & \\
\hline & $(460)$ & & & $(874)$ & & \\
\hline \multirow[t]{2}{*}{ Any Cardiologist Treatment } & & 3484 & & & 2686 & \\
\hline & & $(440)$ & & & $(802)$ & \\
\hline \multirow[t]{2}{*}{ Number of Cardiologists Observed = 1} & & & -10.1 & & & 222 \\
\hline & & & $(283)$ & & & $(1212)$ \\
\hline \multirow[t]{2}{*}{ Number of Cardiologists Observed $\geq 2$} & & & 218 & & & -760 \\
\hline & & & $(371)$ & & & $(1361)$ \\
\hline Mean of the dependent variable & 9,438 & & & 32,967 & & \\
\hline Observations & 181,464 & & & & & \\
\hline
\end{tabular}




\section{A. Across Patients}

\begin{tabular}{lcccccc}
\multicolumn{1}{c}{ Dependent Variable: } & \multicolumn{2}{c}{ 1-year mortality } & & \multicolumn{2}{c}{ Cardiologist assignment } \\
\cline { 2 - 3 } & $\begin{array}{c}\text { Low } \\
\text { predicted } \\
\text { mortality }\end{array}$ & $\begin{array}{c}\text { High } \\
\text { predicted } \\
\text { mortality }\end{array}$ & & $\begin{array}{c}\text { Low } \\
\text { predicted } \\
\text { mortality }\end{array}$ & $\begin{array}{c}\text { High } \\
\text { predicted } \\
\text { mortality }\end{array}$ \\
\cline { 2 - 3 } & & & & & $(3)$ & $(4)$ \\
Number of Cardiologists Observed $=1$ & -0.0005 & -0.0094 & & 0.107 & 0.090 \\
& $(0.0047)$ & $(0.0056)$ & & $(0.0055)$ & $(0.0050)$ \\
Number of Cardiologists Observed $\geq 2$ & -0.0043 & -0.0134 & & 0.196 & 0.176 \\
& $(0.0059)$ & $(0.0070)$ & & $(0.0078)$ & $(0.0074)$ \\
Mean of the dependent variable & & & & & \\
Observations & 0.249 & 0.404 & & 0.288 & 0.230 \\
& 456,272 & 452,811 & & 456,272 & 452,811 \\
\hline
\end{tabular}

\section{B. Across Hospitals}

\begin{tabular}{|c|c|c|}
\hline Dependent Variable: & 1-year mortality & Cardiologist assignment \\
\hline & Low-volume High-volume & Low-volume High-volume \\
\hline
\end{tabular}

Number of Cardiologists Observed $=1$

Number of Cardiologists Observed $\geq 2$

Mean of the dependent variable

Observations

$$
0.330
$$

454,867
(1)

$-0.0054$

(0.0034)

(2)

$-0.0085$

(0.0039)

$-0.0123$

(0.0044)

(0.0045)

0.322

454,216

(3)

(4)

0.0560

$(0.0040)$

(0.0044)

0.138

(0.0064)

(0.0058)

\section{Across Busy \& Slow Dates}

Dependent Variable:

1-year mortality

Cardiologist assignment

Low-volume High-volume Low-volume High-volume

(1)

Number of Cardiologists Observed $=1$

Number of Cardiologists Observed $>=2$
$-0.0099$

(0.0049)
(2)

$-0.0052$

(0.0046)
(3)

0.119

(0.0057)

0.221

(0.0085)
(4)

0.0755

(0.0044)

$\begin{array}{llcc}-0.0141 & -0.0117 & 0.221 & 0.158 \\ (0.0060) & (0.0054) & (0.0085) & (0.0061)\end{array}$

Mean of the dependent variable

$\begin{array}{cccc}0.331 & 0.321 & 0.250 & 0.267 \\ 418,226 & 490,857 & 418,226 & 490,857\end{array}$

All models include full controls described in Table 2, including the number of other specialists observed and hospital x quarter x day-of-week fixed effects. Robust standard errors in parentheses, clustered by hospital. Panel A: Samples are defined by the patient's predicted 1-year mortality from a probit model of mortality and the full set of patient controls. Panel B: Samples are defined by the volume in a given hospital year. Panel C: Samples are defined by whether the number of patients in the hospital on a given date is below or above the daily mean for that hospital. 
Table 8: Other conditions and specialties

Acute Myocardial Infarction Dependent Variable:
Cardiac Dysrhythmia

Any cardiologist

(3)

Number of Most-Common
Specialist Observed = 1
Number of Most-Common
Specialist Observed $>2$
Number of other specialists

$-0.0253-0.0163$

0.1553

$(4)$
0.150

(0.0034) (0.0032)

(0.0059)

(0.0057)

$\begin{array}{llll}-0.0411 & -0.0270 & 0.252 & 0.244\end{array}$

$(0.0040) \quad(0.0037)$

(0.0071)

(0.0070)

$-0.0016 \quad-0.0010$

(0.0005) (0.0005)

(0.0006)

(0.0006)

1-year mortality

Any cardiologist

Stroke

Patient characteristic controls

Mean of dep. var.

Observations

\begin{tabular}{ccc} 
No & Yes & No \\
0.295 & & 0.558 \\
632,297 & & \\
\hline
\end{tabular}

$\begin{array}{cc}(5) & (6) \\ -0.0090 & -0.0075 \\ (0.0023) & (0.0022) \\ & \\ -0.0221 & -0.0195 \\ (0.0027) & (0.0026) \\ & \\ -0.0007 & -0.0007 \\ (0.0003) & (0.0003)\end{array}$

(7) (8)

$0.141 \quad 0.140$

(0.0048) (0.0047)

$0.251 \quad 0.247$

$-0.0012-0.0013$

(0.0005) (0.0005)
(0.0063) (0.0062) 1-year mortality

$-0.0050 \quad-0.0053$

1-year mortality

Any neurologist

\begin{tabular}{|c|c|c|c|c|c|c|c|c|c|c|c|c|}
\hline \multirow{3}{*}{ Dependent Variable: } & \multicolumn{4}{|c|}{ Fractures } & \multicolumn{4}{|c|}{ Hip Fracture } & \multicolumn{4}{|c|}{ Pneumonia } \\
\hline & \multicolumn{2}{|c|}{ 1-year mortality } & \multicolumn{2}{|c|}{ Any orthopedic } & \multicolumn{2}{|c|}{ 1-year mortality } & \multicolumn{2}{|c|}{ Any orthopedic } & \multicolumn{2}{|c|}{ 1-year mortality } & \multicolumn{2}{|c|}{ Any pulmonologist } \\
\hline & (13) & (14) & (15) & (16) & $(17)$ & (18) & (19) & $(20)$ & $(21)$ & $(22)$ & (23) & (24) \\
\hline $\begin{array}{l}\text { Number of Most-Common } \\
\text { Specialist Observed = } 1\end{array}$ & $\begin{array}{l}-0.0236 \\
(0.0022)\end{array}$ & $\begin{array}{l}-0.0165 \\
(0.0021)\end{array}$ & $\begin{array}{c}0.195 \\
(0.0059)\end{array}$ & $\begin{array}{c}0.194 \\
(0.0058)\end{array}$ & $\begin{array}{l}-0.0269 \\
(0.0040)\end{array}$ & $\begin{array}{l}-0.0216 \\
(0.0038)\end{array}$ & $\begin{array}{c}0.149 \\
(0.0069)\end{array}$ & $\begin{array}{c}0.149 \\
(0.0069)\end{array}$ & $\begin{array}{c}0.0021 \\
(0.0021)\end{array}$ & $\begin{array}{c}0.0025 \\
(0.0020)\end{array}$ & $\begin{array}{c}0.0856 \\
(0.0032)\end{array}$ & $\begin{array}{c}0.0853 \\
(0.0032)\end{array}$ \\
\hline $\begin{array}{c}\text { Number of Most-Common } \\
\text { Specialist Observed > } 2\end{array}$ & $\begin{array}{l}-0.0356 \\
(0.0029)\end{array}$ & $\begin{array}{l}-0.0255 \\
(0.0027)\end{array}$ & $\begin{array}{c}0.279 \\
(0.0074)\end{array}$ & $\begin{array}{c}0.278 \\
(0.0073)\end{array}$ & $\begin{array}{l}-0.0388 \\
(0.0049)\end{array}$ & $\begin{array}{l}-0.0312 \\
(0.0048)\end{array}$ & $\begin{array}{c}0.196 \\
(0.0087)\end{array}$ & $\begin{array}{c}0.196 \\
(0.0087)\end{array}$ & $\begin{array}{c}0.0039 \\
(0.0034)\end{array}$ & $\begin{array}{c}0.0051 \\
(0.0033)\end{array}$ & $\begin{array}{c}0.152 \\
(0.0057)\end{array}$ & $\begin{array}{c}0.152 \\
(0.0057)\end{array}$ \\
\hline Number of other specialists & $\begin{array}{l}-0.0003 \\
(0.0004)\end{array}$ & $\begin{array}{l}-0.0001 \\
(0.0004)\end{array}$ & $\begin{array}{l}-0.0048 \\
(0.0005)\end{array}$ & $\begin{array}{l}-0.0048 \\
(0.0005)\end{array}$ & $\begin{array}{c}0.0004 \\
(0.0007)\end{array}$ & $\begin{array}{c}0.0005 \\
(0.0007)\end{array}$ & $\begin{array}{l}-0.0047 \\
(0.0007)\end{array}$ & $\begin{array}{l}-0.0047 \\
(0.0007)\end{array}$ & $\begin{array}{c}0.0021 \\
(0.0004)\end{array}$ & $\begin{array}{c}0.0018 \\
(0.0004)\end{array}$ & $\begin{array}{c}0.0015 \\
(0.0003)\end{array}$ & $\begin{array}{c}0.0014 \\
(0.0003)\end{array}$ \\
\hline $\begin{array}{l}\text { Patient characteristic controls } \\
\text { Mean of dep. var. } \\
\text { Observations }\end{array}$ & $\begin{array}{c}\text { No } \\
0.218 \\
837,383\end{array}$ & Yes & $\begin{array}{c}\text { No } \\
0.575\end{array}$ & Yes & $\begin{array}{c}\text { No } \\
0.258 \\
360,689\end{array}$ & Yes & $\begin{array}{c}\text { No } \\
0.781\end{array}$ & Yes & $\begin{array}{c}\text { No } \\
0.317 \\
999,304\end{array}$ & Yes & $\begin{array}{c}\text { No } \\
0.074\end{array}$ & Yes \\
\hline
\end{tabular}

All models include indicators for the number of physicians and the number of patients observed in the same hospital x quarter $\mathrm{x}$ day-of-week cell. Controls for patient characteristics are the same as those described in Table 2. Robust standard errors in parentheses, clustered by hospital. 


\section{Supplemental Appendix}


Figure A1:

Distribution of Number of Cardiologists

0.4

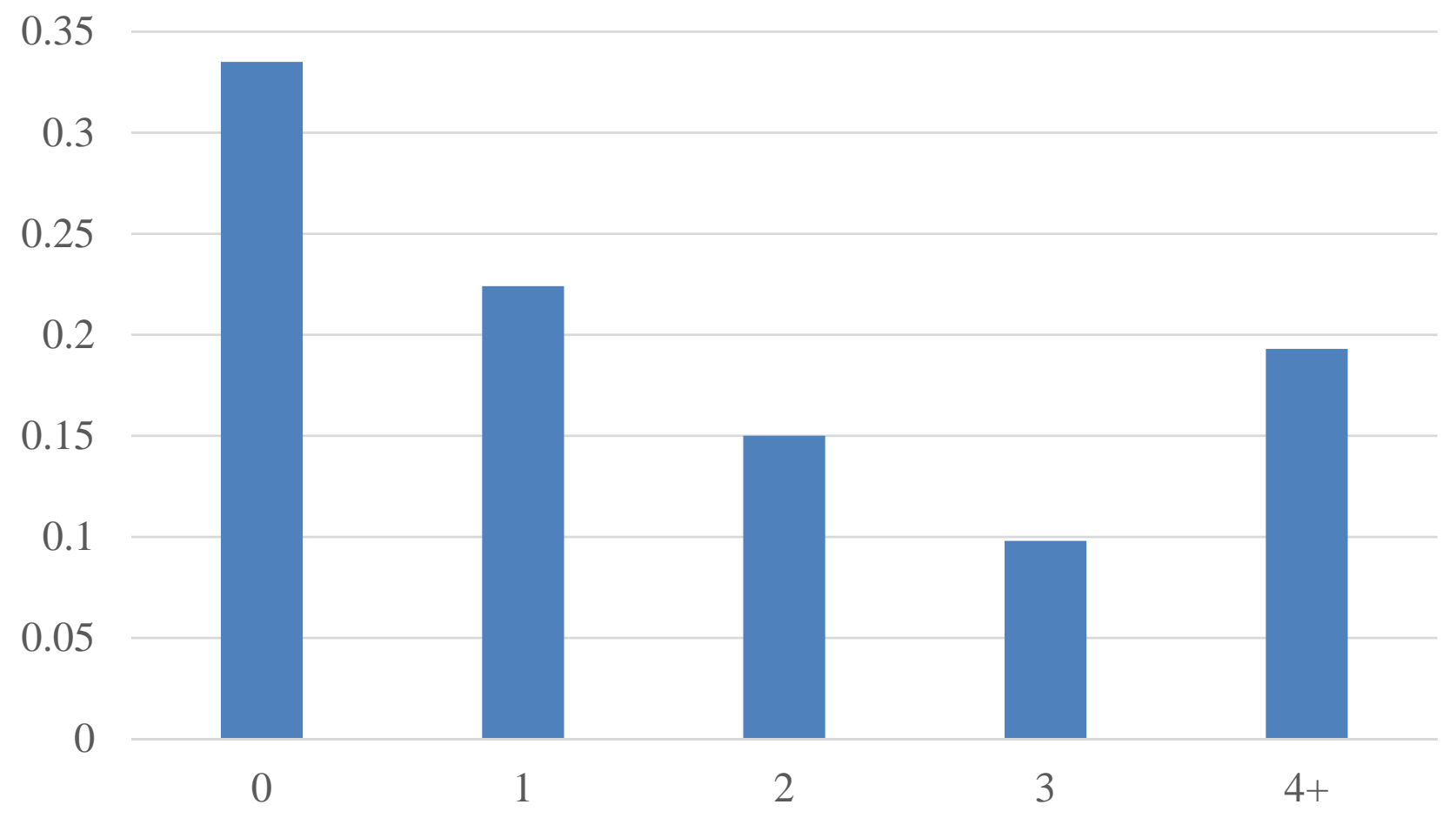

This figure reports the shares of the patient-level data where there were 0 to 4-or-more cardiologists observed available in the analysis sample. 


\section{Figure A2: Cardiologist Attending vs. Cardiologist Availability}

\section{Cardiologist}

Attending

\subsection{5}

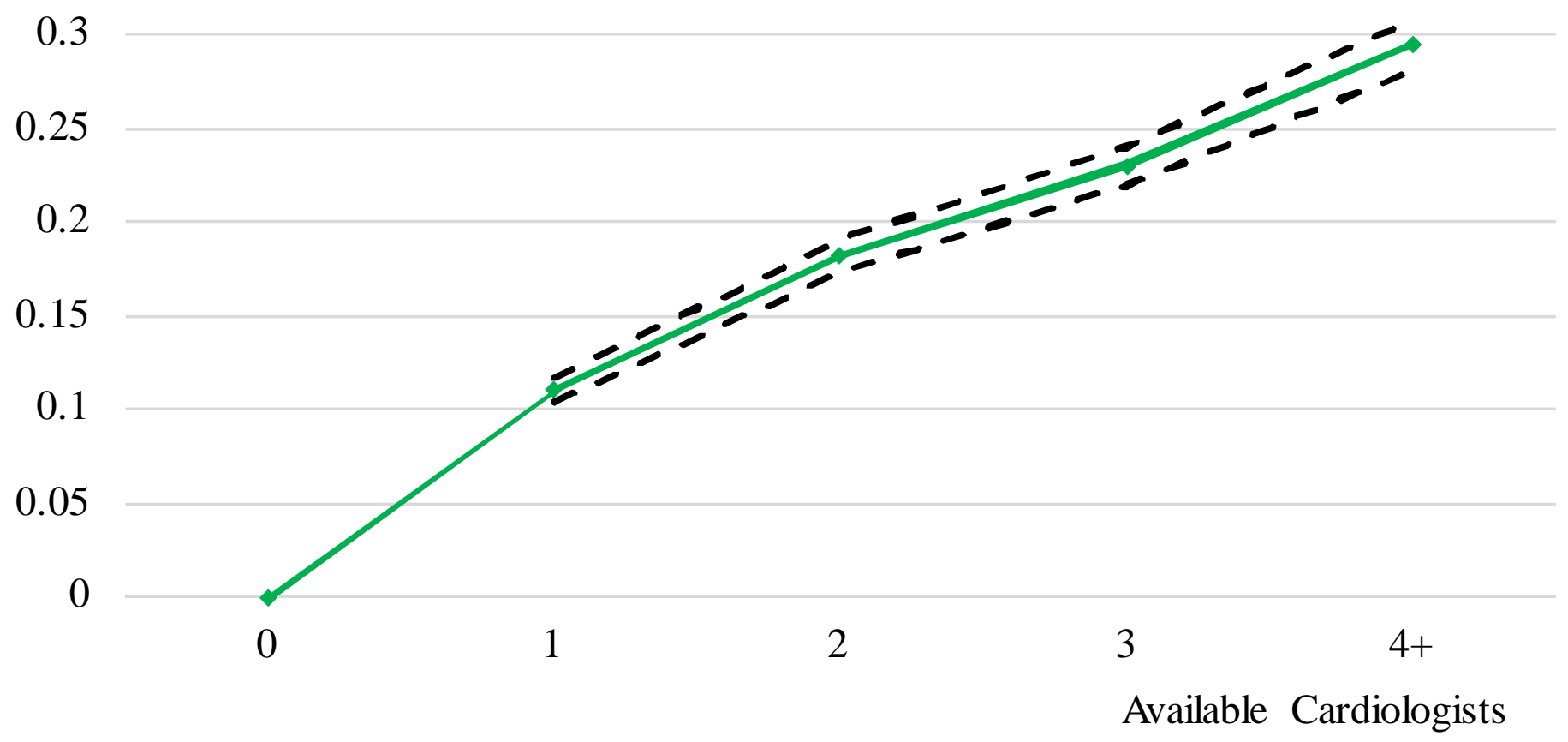

This figure plots coefficient estimates of the relationship between cardiologist assigned as the attending phy sician versus the number of available cardiologists from a model that includes hospital x quarter $\mathrm{x}$ day-of-week fixed effects. Dotted lines represent 95\% confidence intervals calculated using standard errors that were clustered at the hospital level. 
Observations

1. Heart failure patients admitted via the emergency department and were continuously enrolled in fee-for-service Medicare for 12 months prior and 12 months after the beneficiary's first heart-failure admission from 1999-2012

2. Admission year $<2012$ for uncensored outcomes

3. Attending physician admitted at least one more patient on same date for any condition

4. Age $<90$ for variation in treatment intensity 1295848

5. Nonmissing physician characteristics $\quad 1285659$

6. Hospital had $>100$ observations 1180177

7. $>1$ observation in the hospital-quarter-day of week cell 909083

Source: $100 \%$ Medicare inpatient claims. 


\section{A. Patient characteristics}

$\begin{aligned} \text { Demographics } & \text { Age } \\ & \text { White } \\ & \text { Black } \\ & \text { Hispanic } \\ & \text { Male } \\ & \\ \text { Risk } & \begin{array}{l}\text { 1-year lagged spending } \\ \text { 1-year mortality }\end{array}\end{aligned}$

\section{B. Physician characteristics per day}

\author{
Number of physicians observed on same date \\ Training \\ Cardiologists \\ Other specialists \\ Non specialists \\ Number that attended a US medical school \\ Demographics Number of male physicians \\ Average years since graduation (10 years) \\ Volume Average number of patients last year
}

Number that attended a top-50 medical school (Primary Care)

Number that attended a top-50 medical school (Research)
All Heart Failure Inpatients

Analysis Sample

\begin{tabular}{|c|c|c|c|}
\hline $\begin{array}{c}\text { Mean } \\
\text { (1) }\end{array}$ & $\begin{array}{l}\text { Std. } \\
\text { (2) }\end{array}$ & $\begin{array}{l}\text { Mean } \\
\text { (3) }\end{array}$ & $\begin{array}{l}\text { Std. } \\
\text { (4) }\end{array}$ \\
\hline 80.4 & 8.0 & 78.2 & 6.6 \\
\hline 0.86 & 0.34 & 0.85 & 0.36 \\
\hline 0.09 & 0.29 & 0.11 & 0.31 \\
\hline 0.02 & 0.13 & 0.02 & 0.13 \\
\hline 0.43 & 0.50 & 0.46 & 0.50 \\
\hline 12524 & 20348 & 13135 & 20980 \\
\hline 0.36 & 0.48 & 0.33 & 0.47 \\
\hline
\end{tabular}

Observations

Source: $100 \%$ Medicare inpatient claims. Table A1 describes the sample restrictions.

\begin{tabular}{llll}
12.6 & 10.4 & 15.6 & 11.1 \\
1.53 & 2.18 & 1.98 & 2.43 \\
4.34 & 4.75 & 5.61 & 5.17 \\
6.74 & 5.21 & 7.97 & 5.64 \\
2.87 & 3.68 & 3.57 & 4.12 \\
3.52 & 4.59 & 4.39 & 5.11 \\
8.33 & 7.89 & 10.37 & 8.62 \\
\hline & & & \\
10.3 & 8.79 & 12.8 & 9.52 \\
2.13 & 0.48 & 2.12 & 0.40 \\
\hline & & & \\
7.93 & 6.25 & 8.75 & 6.91 \\
\hline
\end{tabular}

$4,054,875$

909,083 
Physician characteristics per day

Training Number of cardiologists

Number of other specialists

Number of non-specialists

Number that attended a top-50 medical school (Primary Care)

Number that attended a top-50 medical school (Research)

Number that attended a US medical school

Demographics Number of male physicians

Average years since graduation (10 years)

Volume Average number of heart-failure patients last year

\begin{tabular}{ll}
8.62 & 2.32 \\
\hline & \\
9.52 & 2.55 \\
0.40 & 0.21 \\
\hline & \\
6.91 & 2.62 \\
\hline
\end{tabular}

Observations
Sample S.D.

(1)

2.43

5.17

5.64

4.12

5.11

8.62

Within Cell S.D.

0.95

1.71

1.86

1.33

1.51

909,083

Source: $100 \%$ Medicare inpatient claims. Table A1 describes the sample restrictions. Column (2) reports the standard deviation of the measures that have been de-meaned within hospital x quarter $\mathrm{x}$ day-of-week cells. 
Table A4: Cardiologists \& 30-day Mortality

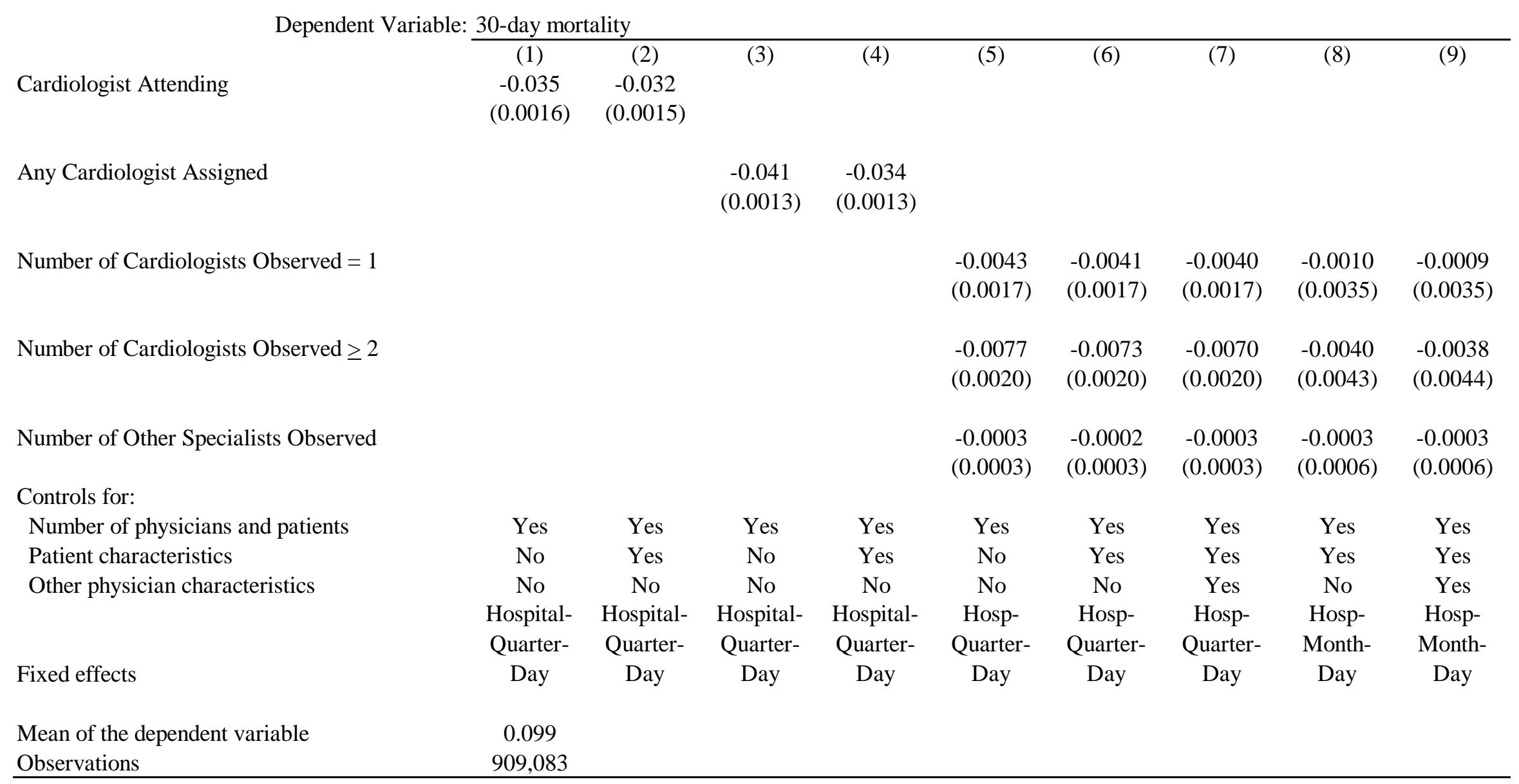

Models control for the number of physicians and patients include indicators for each value observed in the same hospital-date cell. Controls for patient characteristics include those listed in Table 2. Other physician characteristics are described in Table 3. Robust standard errors in parentheses, clustered by hospital. 


\begin{tabular}{|c|c|c|c|c|c|c|c|c|}
\hline \multirow[t]{2}{*}{ Dependent Variable: } & \multicolumn{2}{|c|}{$\begin{array}{c}\text { Operation on the } \\
\text { cardiovascular system }\end{array}$} & \multicolumn{2}{|c|}{$\begin{array}{c}\text { Cardiac } \\
\text { catheterization } \\
\end{array}$} & \multicolumn{2}{|c|}{$\begin{array}{c}\text { Number of procedures } \\
\text { (30-days) } \\
\end{array}$} & \multicolumn{2}{|c|}{ Hospital charges } \\
\hline & (1) & $(2)$ & (3) & (4) & (5) & (6) & (7) & (8) \\
\hline Cardiologist Attending & $\begin{array}{c}0.105 \\
(0.0053)\end{array}$ & & $\begin{array}{c}0.064 \\
(0.0026)\end{array}$ & & $\begin{array}{c}0.256 \\
(0.016)\end{array}$ & & $\begin{array}{r}5578 \\
(469.6)\end{array}$ & \\
\hline Any Cardiologist & & $\begin{array}{c}0.2682 \\
(0.0076)\end{array}$ & & $\begin{array}{c}0.2360 \\
(0.0057)\end{array}$ & & $\begin{array}{c}1.044 \\
(0.0282)\end{array}$ & & $\begin{array}{l}11586 \\
(528)\end{array}$ \\
\hline $\begin{array}{l}\text { Mean of the dependent variable } \\
\text { Observations }\end{array}$ & $\begin{array}{c}0.217 \\
909,083\end{array}$ & & 0.082 & & 0.997 & & 24829 & \\
\hline
\end{tabular}

All models include the full set of patient and environment controls described in Table 2, including hospital x quarter x day-of-week fixed effects. Robust standard errors in parentheses, clustered by hospital. 
Table A6: Cardiologist Availability \& Facility Spending

Dependent Variable:

Index admission inpatient \& outpatient facility spending

Number of Cardiologists Observed $=1$

(1)

134

(36.8)

(2)

120

(36.5)

362

(51.5)

325

Number of Cardiologists Observed $\geq 2$

Number of Other Specialists Observed

40.2

(9.77)

37.7

(9.75)

Yes

No

No

7140

909,083

Patient characteristics

Other physician characteristics

40.7

(10.1)

Observations

Yes 1-year inpatient \& outpatient facility spending

(4) (5) (6)

$145-117 \quad 112$

(146) (143) (143)

$\begin{array}{cccc}307 & 181 & 104 & 89.3 \\ (50.8) & (172) & (168) & (169)\end{array}$

$\begin{array}{cccc}307 & 181 & 104 & 89.3 \\ (50.8) & (172) & (168) & (169)\end{array}$

40.9

23.4

33.5

(26.8) (26.7) (26.8)

Mean of dependent variable

No Yes

Yes

No No $\quad$ Yes

All models include indicators for the number of physicians and the number of patients observed in the same hospital x quarter $\mathrm{x}$ day-of-week cell. Controls for patient

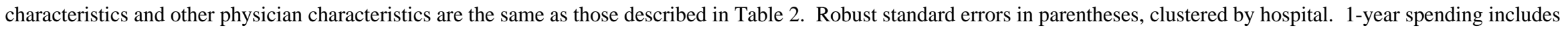
the initial hospital stay. Facility spending does not include physician fees. 
Dependent Variable: 30-day readmission

$\begin{array}{ccc} & (1) & (2) \\ \text { Cardiologist Attending } & -0.017 & -0.015 \\ & (0.0020) & (0.0020)\end{array}$

Any Cardiologist Assigned

$\begin{array}{cc}-0.010 & -0.0048 \\ (0.0017) & (0.0017)\end{array}$

Number of Cardiologists Observed $=1$

$\begin{array}{ccc}0.0001 & 0.0001 & 0.0001 \\ (0.0023) & (0.0022) & (0.0023) \\ & & \\ -0.0004 & -0.0002 & -0.0002 \\ (0.0026) & (0.0026) & (0.0026) \\ & & \\ 0.0007 & 0.0006 & 0.0007 \\ (0.0004) & (0.0004) & (0.0004)\end{array}$

Controls for:

Patient characteristics

Other physician characteristics

$\begin{array}{ll}\text { No } & \text { Yes } \\ \text { No } & \text { No }\end{array}$

$\begin{array}{ll}\text { No } & \text { Yes } \\ \text { No } & \text { No }\end{array}$

$\begin{array}{lll}\text { No } & \text { Yes } & \text { Yes } \\ \text { No } & \text { No } & \text { Yes }\end{array}$

Mean of Dep. Var.

0.217

Observations 909,083

All models include indicators for the number of physicians and the number of patients observed in the same hospital x quarter x day-of-week cell. Controls for patient characteristics and other physician characteristics are the same as those described in Table 2. Robust standard errors in parentheses, clustered by hospital. 1-year spending includes the initial hospital stay. Robust standard errors in parentheses, clustered by hospital. 